\title{
Beyond manpower planning: ROA's labour market model and its forecasts to 2002
}

Citation for published version (APA):

de Grip, A., \& Heijke, J. A. M. (1998). Beyond manpower planning: ROA's labour market model and its forecasts to 2002. Researchcentrum voor Onderwijs en Arbeidsmarkt, Faculteit der Economische Wetenschappen. ROA Working Papers No. 6E https://doi.org/10.26481/umarow.199806E

Document status and date:

Published: 01/01/1998

DOI:

10.26481/umarow.199806E

Document Version:

Publisher's PDF, also known as Version of record

\section{Please check the document version of this publication:}

- A submitted manuscript is the version of the article upon submission and before peer-review. There can be important differences between the submitted version and the official published version of record.

People interested in the research are advised to contact the author for the final version of the publication, or visit the DOI to the publisher's website.

- The final author version and the galley proof are versions of the publication after peer review.

- The final published version features the final layout of the paper including the volume, issue and page numbers.

Link to publication

\footnotetext{
General rights rights.

- You may freely distribute the URL identifying the publication in the public portal. please follow below link for the End User Agreement:

www.umlib.nl/taverne-license

Take down policy

If you believe that this document breaches copyright please contact us at:

repository@maastrichtuniversity.nl

providing details and we will investigate your claim.
}

Copyright and moral rights for the publications made accessible in the public portal are retained by the authors and/or other copyright owners and it is a condition of accessing publications that users recognise and abide by the legal requirements associated with these

- Users may download and print one copy of any publication from the public portal for the purpose of private study or research.

- You may not further distribute the material or use it for any profit-making activity or commercial gain

If the publication is distributed under the terms of Article $25 \mathrm{fa}$ of the Dutch Copyright Act, indicated by the "Taverne" license above, 


\section{Beyond Manpower Planning: \\ ROA's Labour Market Model and its Forecasts to 2002}

ROA-W-1998/6E

Andries de Grip and Hans Heijke*

* The authors wish to thank Gerry Hughes, of the ESRI in Dublin, and their colleagues Lex Borghans and Patrick van Eijs, for their extensive comments on earlier versions of this paper. Earlier versions were presented at the Fifth IIRA European Regional Industrial Relations Congress, Dublin, 26-29 August, 1997 and the Canadian Occupational Projections System's Federal/Provincial Technical Conference, Ottawa, 11-12 June, 1998.

Research Centre for Education and the Labour Market

Faculty of Economics and Business Administration

Maastricht University

Maastricht, December 1998 
ISBN 90-5321-246-9

SEC98.085/HH 


\section{Contents}

Abstract

1 Introduction

2 Matching education and the labour market: some policy approaches 4

3 The importance of labour market information 6

$\begin{array}{lll}3.1 \text { Educational choices } & 6\end{array}$

3.2 Recruitment policies $\quad 8$

3.3 Educational institutes and intermediary organisations 9

3.4 More stable flows into the education system 10

4 ROA's labour market information system 13

$\begin{array}{lll}4.1 \text { Basic principles } & 13\end{array}$

4.2 Theoretical foundations 15

4.3 General structure of the forecasting model 22

4.4 Occupational and educational classification 25

5 Labour demand and supply submodels $\quad 27$

5.1 Expansion and substitution demand forecasts $\quad 27$

5.2 Replacement demand forecasts $\quad 35$

5.3 Forecasts of inflow of school-leavers 39

5.4 Labour market indicators $\quad 40$

6 Employment forecasts by educational levels 43

7 Students' prospects and recruitment problems up to $2002 \quad 48$

7.1 Labour market prospects for school-leavers 48

7.2 Recruitment problems 53

8 Sensitivity to cyclical fluctuations and opportunities to switch 56

9 Evaluation $\quad 60$

10 Conclusions $\quad 64$

$\begin{array}{ll}\text { References } & 65\end{array}$ 


\section{Abstract}

This paper describes the forecasting model of the Research Centre for Education and the Labour Market (ROA), which has been developed for making forecasts about developments of the labour market position of different types of education with respect to the Dutch labour market. Every two years, ROA compiles forecasts of changes in the labour market in the medium term, differentiated by a large number of economic sectors, occupational classes and types of education to illustrate the meaning of the information.

The paper aims particularly to describe the objectives, the basic principles, the theoretical foundations and the structure of ROA's forecasting approach and the major labour market indicators in more detail. The forecast labour market developments for the types of education up to the year 2002 will also be presented. Due to the low level of aggregation used, these forecasts provide very useful information for people who are involved in decisions about educational investments. 


\section{Introduction}

A well-trained workforce is generally seen as an important precondition for achieving economic growth. But a workforce with higher education does not necessarily imply higher economic growth. The productive value of education is in fact dependent not only on the level of the education but also on the subjects studied, and on which occupation is practised with that education. Moreover, educating the population requires educational facilities, which must be provided with resources which are then denied to other productive purposes.

The great diversity of types of education and occupations means that optimizing the contribution of education to economic growth involves solving a complex matching problem in the labour market. In a perfectly operating labour market, equilibrium would be achieved automatically. In practice the functioning of the labour market is obstructed by a wage structure which is relatively inflexible, limited opportunities for substitution between submarkets, high adjustment costs, the existence of various institutions intended to provide protection and security and the limited transparency of market events for all those who are involved. A particular problem in relation to the transparency of the labour market for students, firms and educational decision-makers is that the benefits of investments in education and training only become evident in the future.

In the past it was thought that the coordination between the education system and the labour market could be solved by planning. One well-known approach is the 'manpower requirement model' as applied, for example, by Parnes (1962), who developed a manpower planning model on the basis of the input-output structure of the economy. After a number of steps, the labour requirements in the various occupations and the educational qualifications which are demanded for these occupations are determined. The labour requirements are then compared with forecasts of the working population and the flow of graduates from the various types of training onto the labour market.

Partly due to the severe criticism on the initial manpower requirements approach the planning function has disappeared almost completely. Van Eijs (1994) argues that nowadays manpower forecasting in the West is considered to have two functions: a 'policy function' and an 'information function'. The policy function refers to the usefulness of manpower forecasts as 'a point of reference' for policy recommendations for policy makers who have to take decisions on educational investments or other educational or labour market policies (Wilson, 1993). The information function is primarily intended to assist in occupational or educational guidance (cf. Dekker et al., 1993), although it could also inform firms on possible future recruitment problems due to the scarcity of workers with a particular educational background.

This development is evident in the completely changed role of manpower forecasting in the 
various countries where occupational and/or educational forecasts are still made (see OECD, 1994 and, especially for the approach which is adopted in the United Kingdom, Germany and the Netherlands, Heijke, 1994). This paper will describe the forecasting model of the Research Centre for Education and the Labour Market (ROA), which has been developed for making forecasts with respect to the Dutch labour market. Every two years ROA compiles forecasts of changes in the labour market in the Netherlands in the medium term, differentiated by a large number of economic sectors, occupational classes and types of education. The paper aims particularly to describe the objectives, the basic principles, the theoretical foundations and the structure of ROA's forecasting approach and the major labour market indicators in more detail. It also presents the forecast labour market developments for the various types of education up to the year 2002 which were published at the end of 1997 (ROA, 1997) to illustrate the meaning of the information. ${ }^{1}$

The forecasts of ROA focus particularly on above mentioned information function of the manpower requirements approach, aiming at 'increasing the transparency of the match between education and the labour market' (Dekker et al., 1993). The labour market data are incorporated in a variety of information products for vocational and educational guidance purposes. ROA's own biennial report, The labour market by education and occupation, is intended rather for policy-making bodies, filling the policy function of the manpower requirements approach which was described above.

In several countries the labour market forcasts are restricted to occupational forecasts (Cf. Hughes, 1993 and van Eijs, 1994). ROA's forecasting model however includes the transformation of the occupational forecasts into the demand for workers by type of education. This makes it possible to indicate the future changes in the skill requirements of the working population. Furthermore ROA's forecasts encompass not only the expansion demand but also the replacement demand. The sum of the replacement and expansion demand, the number of job openings, is matched against predictions of the inflow of school-leavers from each type of education.

Every effort has been made to give the ROA forecasts a more robust theoretical foundation than traditional manpower forecasting, although further improvements in this field are required. In the theoretical framework which underlies ROA's forecasts, substitution processes are incorporated in the forecasts of the future labour market situations for the various types of education. In this way neo-classical ways of reasoning are incorporated in the framework of manpower forecasting, which traditionally lacks any substitution possibilities (Blaug, 1967). This theoretical foundation builds particularly on concepts relating to job matching theory and disequilibrium theory (Borghans, 1993; Borghans and Heijke, 1996; Borghans and Willems, 1998; van Eijs and Heijke, 1996).

1. The paper as a whole is in a sense an update of the chapters in Heijke (1994) that relate to the ROA, and with respect to sections 1 through 4 of Heijke (1996). 
Moreover, ROA's labour market forecasts are incorporated in a 'labour-market information system', which also indicates the risks related to the uncertainty of future labour market developments (e.g. the cyclical fluctuations of employment). Finally, ROA is able to build its models on a much better data input and more sophisticated econometric models than traditional manpower forecasts. In particular the annual Labour Force Survey produced by Statistics Netherlands and the large-scale school-leaver surveys that ROA coordinates contribute to the improved data-input. Instead of the fixed coefficient models, explanatory models have been developed corresponding to the improved theoretical framework which underlies ROA's forecasts.

Finally, occupational and educational classifications have been developed based on theoretical foundations. So far as possible, these classifications bring together groups of workers who operate de facto in the same labour market segment. People from types of education which are very different in name might find jobs in one segment of the labour market. Explicit recognition of this market structure, and thus taking these types of education together in the classification, provides a better picture of the market situation than a forecast in which supply and demand for such types of education are treated separately.

The remainder of this paper is structured as follows. First, section 2 outlines some policy approaches which have been taken since the 1960s to improve the match between the education system and the labour market. Section 3 deals with the relevance of labour market information for the various actors on the supply and the demand side of the labour market and the educational and intermediary organisations, respectively. Section 4 discusses the principles underlying ROA's labour market forecasts, the theoretical foundations, the general structure of the forecasting model and the 'labour market related' occupational and educational classifications used. Section 5 discusses the various demand and supply models, which refer to the expansion demand, substitution demand, replacement demand and the inflow of newcomers on the labour market respectively. Furthermore, the 'labour market indicators' which are central in ROA's labour market information system are presented. Section 6 describes the expected upgrading of the skill structure of labour demand by presenting the 'expansion demand' forecasts by educational level up to the year 2002. This section also presents the various components of the changes in employment by educational level. Section 7 gives an overview of students' prospects and the recruitment problems by type of education up to the year 2002. Section 8 considers two labour market indicators, of 'sensitivity to cyclical fluctuations' and 'opportunities to switch', for the various types of training. In order to give an impression of the reliability of the forecasts for the intended users, section 9 describes the main evaluation results of previous forecasts made for the period 1989-'94. Section 10 contains the conclusions. 


\section{Matching education and the labour market: some policy approaches}

The allocation process on the labour market is characterized by serious imperfections. Due to the heterogeneous character of the market and a range of inflexibilities of both supply and demand, the labour market could suffer serious mismatch phenomena. While some workers face unemployment, firms may have recruitment problems for other skill categories. For this reason public policies continuously pay attention to the coordination between the educational system on the one hand, which largely determines the skills supplied and, on the other hand, the demand in the labour market for the various skill categories.

As mentioned in the introduction, in the 1960s the remedy for the poor match between the educational system and the labour market was sought mainly in the establishment of a planning system. In particular the 'manpower requirement approach', initiated by the OECD, was considered to be an important tool in educational planning (van Eijs, 1994). In this approach the planning begins with the determination of the target growth in the Gross National Product over a period of several years. From this, after a number of steps, the labour requirements in the various occupations and the educational qualifications which are required for these occupations are determined. The labour requirements are then compared with forecasts of the working population and the flow of graduates from the various types of training onto the labour market. The graduate-flow forecasts are compiled with the aid of a student-flow model that describes the flows of students within the educational system. From the differences between future labour requirements and the future working population, allowing for the expected flows from the educational system, it is possible to extract the required information on the extra training initiatives which are needed to achieve the desired growth in the Gross National Product.

Various methodological and fundamental objections have been made to the manpower requirements approach. The methodological objections focus particularly on the fixed coefficients, which are used in the forecasting models to translate economic development into changes in employment differentiated by training and occupation, and on its mechanical concept of labour market functioning, in which there is no place for the working of substitution and other adjustment processes (Blaug, 1967). The fundamental objections are that future developments are not in fact sufficiently predictable, and that an exclusive relationship between job requirements and training is assumed without adequate justification.

These objections, and the lack of sufficient statistical data for the estimation of the forecasting models, led to the rejection of the planning concept. A flexible approach to education was advocated, one which would enable an adequate response to uncertain future developments. According to the latter concept, initial training courses should be 
broadened so that each could lead to a broad range of occupations. Any discrepancies which might arise between specific, and mutable, job demands and the qualifications of workers would have to be dealt with by means of short training courses and on-the-job training.

The broader scope of initial training courses would speed the matching process in the external labour market, which would lower the search costs for both sides of the market, with the ultimate result that the visible surpluses and shortages of workers with a particular educational background should become smaller. However, if all graduates were to find the job which corresponded best to their capabilities, the less vocation-specific character of these training courses would also result in a poorer average match between the occupation-specific job requirements and the knowledge and skills of those filling the jobs, which would lead to lower productivity in carrying out their functions. Firms wishing to reverse this loss of productivity would have to provide supplementary training for the workers concerned. Increased market efficiency is thus achieved at the price of reduced economic effectiveness in the form either of lower productivity or of higher adjustment costs. In such a situation one has to seek the optimal trade-off between flexibility and productivity or lower adjustment costs (de Grip and Heijke, 1991). The flexibility concept would thus have to be implemented within certain limits, meaning that optimal labour market relations would not exclude a degree of market segmentation by education and occupation. The rigidity of the relative wage rates, the high cost of adjustment and the long time required for the supply of labour to adapt to changes in demand, because of the length of training courses in initial education, would in this situation continue to be an impediment to the achievement of a perfect match between demand and supply.

As a result of the failings of the macro-economic policy that was put into place to counter the results of the oil crisis in the 70s, there has been more interest in improving the adaptability of the supply side of the economy. The process of industrial restructuring and renewal had to be promoted and the working of the market generally stimulated. It was no longer thought that a policy of direct intervention was required to ensure the correspondence of the education system to the labour market, but rather that the provision of adequate information would make the labour market more transparent for those choosing a course of study and others investing in education. This transparency would perhaps make the supply of labour more responsive to changes on the labour market. It would then automatically conform better to the new employment opportunities. Moreover, the labour market forecasts give firms an indication of the future risk of labour recruitment problems for the various skill categories, which enables them to anticipate future shortages, for example by internal training and outflow reduction policies for categories of workers for which future shortages are forecast. 


\section{The importance of labour market information}

\subsection{Educational choices}

Research in the Netherlands has shown that secondary and tertiary students have at least some interest in the labour market outlook when they are choosing a course of study or occupation. A study by Kodde and Ritzen (1986), for example, shows that, for students from the second phase of secondary education, the chances of getting a job and being able to practise a particular occupation are important motives in deciding whether or not to go further with their study. Earnings prospects, however, appeared to be given less weight. ${ }^{2}$ These results have been substantially confirmed by Herweijer and Blank (1987), whose research found a significant positive correlation between unemployment and the numbers going on to further education. From these results one would conclude that further study is to some extent seen as a way to avoid unemployment, and that people expect that gaining a higher diploma will increase their opportunities on the labour market.

Recently, results from an extensive study of high school graduates from the various parts of the Dutch secondary education system have become available (de Jong et al., 1992). The research provides information on the nature of the choices which students make as regards their further educational or occupational careers, and the motives behind these choices. The results of this research show, among other things, that the study plans of students have little relation to their social backgrounds. Important motives for going further with education, along with 'utilizing talents and self-development', include a number of considerations relating to possibilities in the future, such as 'to gain a higher position', 'more chance of getting a job' and 'high income'.

All these studies say something about the role of the labour market in making choices about continuing education. Unfortunately there is less information available regarding the role of labour market expectations in choosing a particular course of study. There are however a number of studies which give us some indications. In their inventory of previous research, Verrijdt and Diederen (1987) found that the regional employment structure had an influence on the actual school choice and occupational choice of ex-students in Junior Technical Secondary Education and Junior General Secondary Education. A study by Willems and de Grip (1994) of the motives underlying general secondary school students' decisions to continue in further education in a technical field showed that the images which young people have of both the labour market position of these studies and the qualitative aspects of the work are important in the choices they make.

2. Nevertheless, a later study by Oosterbeek and Webbink (1995) using the same data from 1982 and a similar set of data from 1991 has shown that future income does play a role in the decision to undertake higher education (for the 1991 data, see also de Jong et al. (1992). 
Another indication can be found in a study by Gijselaers and Ramaekers (1991) among second year economics students at Maastricht University. This research shows that the choice of their 'major' - i.e., whether to graduate in general economics, business economics or international management - is largely determined by the desire to undertake an interesting course with which one can practise an occupation which is in itself interesting. Other factors which played an important role in the choice were the possibility of choosing from a broad range of occupations with a particular qualification, and that graduates in the field have a high probability of getting a job. The income that can be earned is clearly less important. The quality and the degree of difficulty of the course also appear to play a less important role in the choice of study. Analogously, to some extent, to above mentioned study by Willems and de Grip, economics students were also asked about the image they had of the labour market. It was found that they were reasonably able to compare the labour market prospects of economists - in terms of employment and income - with those of graduates from other types of university education.

Finally we should mention one recent exploratory study by Webbink (1998), who examined the decisions made by matriculating secondary students regarding tertiary education. $\mathrm{He}$ examined how decisive the expected probability of obtaining a job was for the educational choices actually made, and the extent to which choices were in accordance with ROA's labour market prospects at the time each choice was made. According to this exploratory study, educational choices are determined more by matriculant's stereotype images of future job possibilities for people with the type of education in question than by the latest information on labour market prospects for that type of education.

These research results indicate that students apparently pay considerable attention to their opportunities on the labour market when they are deciding whether to study further, and that they are also able to form a general, if rather stereotyped, picture of their prospects on the labour market with the further education which might be involved. It is hardly surprising that the picture which they have is not always accurate, because the labour market data which has traditionally been available is incomplete and generally not suited for the choices which students must make. ${ }^{3}$ The data on registered unemployment, for example, does not include all those who are seeking work and have not found it, and the data is also far from 'clean' because some of those registered have already found work, although this is often temporary. Another very important limitation is that the data which was available until a few years ago generally related only to the past, but for those choosing a course of study it is the situation at the end of this course, thus a situation which has yet to emerge, which is relevant. This data is now available in the Netherlands from the reports of the medium-term forecasts which ROA has been making since the late 1980s. These forecast the labour market prospects of types of education, covering the full width of the labour market. The

3. The points on which the images which students have correspond with, and differ from, reality are discussed in ROA (1995), Chapter 5. 
information from these reports, in the form of various information products, ${ }^{4}$ is in fact becoming increasingly popular in the field of vocational and educational guidance, but its specific impact on the quality of the educational and vocational choices of students in secondary and higher education has not yet been evaluated, except for Webbink's very limited attempt in relation to the situation as it was three years ago.

A good supply of information as regards the labour market is important for secondary and tertiary students. In fact the availability of good labour market information can not only benefit the choice of a study or occupation, but can also contribute to reducing the gap between expectations and the reality after graduation. It would produce a better allocation of secondary and tertiary students to the various types of education, in the sense that fewer of those making study choices would mistakenly undertake courses because they have an excessively optimistic idea of the opportunities they offer in the labour market, and also that fewer would mistakenly avoid courses of further education which appear to them to be associated with unfavourable labour market signals. ${ }^{5}$ The ROA reports, which are primarily designed to assist students in their vocational and educational choices, are also intended to improve the labour market allocation processes in this sense.

\subsection{Recruitment policies}

Firms and other organisations which are actors on the demand side of the labour market also have an interest in the availability of information on future labour market. It is important for these actors that there should be a sufficiently large potential workforce to fill the available work places, and that the workers who are recruited should have the specific knowledge and skills to enable them to produce the highest possible productive performance. These interests are in part already served by improving the allocation of students between the various types of education, by making labour market data available which gives a realistic picture of the possibilities on the labour market. The interest of trade and industry, and of the government as an employer, will focus mainly on the flows from the education system onto the labour market, and on the knowledge and skills which this new labour supply has, in relation to the specific demands which they will meet in carrying out their work.

The confrontation between the forecast developments of demand and supply also gives an

4. The reports that ROA publishes are intended primarily for those involved in policy-making in relation to the match between the educational system and the labour market. However the data contained in the reports is incorporated in a variety of information products for educational and vocational guidance purposes, such as pamphlets, teaching materials, computer programmes on CD-ROMS etc. These products are compiled and distributed by the LDC in Leeuwarden, which specialises in this field.

5. For a fundamental analysis of this problem, see Borghans (1993). 
indication of the future recruitment requirements and the risk of recruitment problems for particular types of education (see section 7). Shifts in the relative scarcity of the various skill categories could imply that firms will not be able to recruit sufficient workers with the educational background required. These supply shortages may force them to restrict the level of production, where other alternatives such as recruiting workers with a less suitable educational background or asking the workforce to work overtime are not able to solve the supply shortages. However if firms anticipate future shortages, more 'preventive' policies could enable than to cope with these shortages. These preventive policies might refer to the additional training of the current workforce, policies which reduce the outflow of the labour market or the external mobility of workers to other economic sectors or create training capacity which enables the firm to recruit workers who do not yet have the required educational background. As these preventive policies could also be important instruments to improve the allocation process on the labour market, ROA also translated the confrontation between the labour supply and demand forecasts into an indicator of future recruitment problems, which explicitly signals future recruitment problems.

\subsection{Educational institutes and intermediary organisations}

Finally, the availability of information on the future labour market developments is also relevant for educational institutes and intermediary organisations, such as the (public) employment services. Educational institutes, and perhaps even more their most important financier, the government, want the education which is provided to produce a social return of a certain level. Part of this is that the qualifications which are awarded should have some useful applicability in the labour market. They will try to avoid a situation in which, on the one hand, funding is maintained for educational facilities which offer types of education with which it will later be difficult to get work while, on the other hand, there is insufficient room for the expansion of types of education characterized by favourable labour market prospects. The employment services have an interest in seeing that the education system, in terms both of content and the allocation of students between the various types of education, contributes to minimizing unemployment and seeing that the available vacancies are appropriately filled.

The specific information requirements of such institutions derive from their specific responsibilities for policy in relation to optimising the match between education and the labour market. However these responsibilities may to some extent overlap. The institutions which implement an educational or training policy are interested mainly in the availability of information on changes in employment levels and on the replacement demand, differentiated by function or occupation, and the educational prerequisites for employment in these posts. The institutions which are involved in carrying out labour market policies will mainly need information on current and threatened discrepancies between the flows coming from the various types of education onto the labour market and the need for new workers as a result in changes in employment levels in the various segments of the labour market. 
As we have already seen in relation to the labour market information for educational and vocational choices, the information which is required if the institutions named above are to be able to take measures to improve the match between the education system and the labour market is far from adequate. This is not surprising, because in both cases the information required is quite similar. The lack of a good supply of information means that putting a policy in place as regards the mutual tuning of the education system and the labour market could be compared with setting a course from an uncertain position for an equally uncertain destination, on a turbulent sea and in thick mist. Naturally a safe and certain course is a matter of chance rather than the rule.

An improvement in the supply of information, of the sort that which ROA seeks to realize in the Netherlands through its Information System on Education and the Labour Market, would make the labour market more transparent for those choosing a course of study, and for educational institutions, employment services, government authorities and trade and industry. It would enable them to give a more rational foundation to their decisions, and the outcomes of their actions would be qualitatively better, with fewer educational choices being regretted in retrospect, lower costs for recruiting new employees and setting them to work, a more motivated workforce, higher productivity, lower unemployment and less hardto-fill vacancies. This is emphatically not to say that improvements in the supply of information will bring utopia within reach. The world in which the improved labour market information must be placed is too uncertain and complex for an entirely certain position and a fixed and safe course ever to be achievable. The most that can be expected is a significant improvement in the current sub-optimal match between the education system and the labour market.

\subsection{More stable flows into the education system}

An improvement in the information on changes in demand and supply on the labour market would not only lead to a qualitatively better correspondence between the education system and the labour market, as described in the previous paragraph, it could also stabilize the flows of students entering the various types of education. This would occur if the labour market segments involved exhibit a more stable pattern, as compared to the current often highly variable educational preferences of students, and if these students, as a result of the availability of better labour market information, were to be more influenced by the labour market prospects than is the case now. Greater stability may also result where there is a so-called cobweb cycle in students' educational preferences. This is a situation in which students base their educational choices on the labour market situation at the time they make their choice rather than on the labour market situation when they will finish the chosen course. The self-sustaining dynamic process which results, and which will be described in more detail below, can be dampened by providing information on the future labour market prospects of types of education (there are certain conditions for this to work, 
which cannot be gone into here). ${ }^{6}$ This section will examine this potential stabilising influence of labour market information on the flows of students entering the various types of education in more detail.

Students' interest in a particular type of education is often very changeable, as noted above. Over time, a wave pattern can be seen in the flows of new students entering many types of education. This oscillating pattern leads to uncertainty regarding the annual flows entering the various types of education. As would be expected, the educational institutes are therefore inclined to maintain a teaching capacity - in terms of people and facilities which is somewhat greater than is strictly necessary, so as to be able to cope without difficulty with any unexpected increase in the inflow. In fact a higher average educational capacity would also be expected if these fluctuations were entirely predictable, because initiating and closing down teaching capacity entails adjustment costs. Any increase in the stability of the flows of new students would thus produce savings in the costs of education as a result of the greater predictability of the inflows and the reduced risk of having to meet adjustment costs.

Stabilisation of the inflows can also be favourable for the labour market, where students' study choices exhibit the cobweb cycle which was mentioned above. The cobweb cycle can be visualized using figure 1, taken from a study by de Grip (1987, p. 54). In the figure the flow of time is from top to bottom. The left-hand blocks relate to successive situations in the labour market. The right-hand blocks refer to the situations in the types of education concerned - in this figure a 4-year course for a skilled trade. The figure begins with a situation in which there is a shortage of tradesmen and, as a result, wages are high. This will lead many people to choose this particular course. At the end of the course the lastyear classes will be large and there will be large flows of graduates entering the labour market. If the demand for these tradesmen has not changed significantly in the meantime, there will be an oversupply of labour in that part of the labour market and the wages will come under downward pressure. Now only a few people will choose this course. At the end of the 4-year training period, this will mean small classes of last-year students, and limited flows entering the labour market. The situation in the labour market has now returned to that at the beginning of the cycle, with a shortage of tradesmen and high salaries.

The cobweb cycle described in the figure shows why periods with large over-supplies of workers with a particular educational background can alternate with periods with large shortages of the same workers. It shows how adjustments in a labour market which is not in equilibrium, in the form of increased or reduced participation in education, can themselves lead to new disequilibria in the future. These dynamic disequilibria entail not only increased educational costs, as mentioned above, but also costs for social security benefits for the unemployed during periods of excess supply and losses of production during periods of

6. See Borghans (1993), Chapter 15. 
shortages. There are thus potential advantages for society if these cobweb cycle oscillations in the flows entering educational courses can be countered.

From this description of the cobweb cycle, the factors which are responsible for the existence of a cobweb cycle in the education system can easily be deduced. In the first place, there must be a clearly defined sub-market for people with a particular kind of training. This is the case if the graduates from the type of education concerned look for work within a limited field and the workers in that field are recruited from among the graduates from that type of education. There is then a one-to-one relationship between the type of education and the relevant segment of the labour market. The second condition for the creation of a cobweb cycle is that the training lasts relatively long. The longer the course is, the larger the peaks and troughs of the cobweb cycle will be. The last important condition for the formation of a cobweb cycle is, as was noted above, that people who are choosing a course of study respond to the labour market situation at that time, rather than to the prospects as they will be when they have completed the course.

Figure 1

Cobweb cycle in a sub-market, for a 4-year course

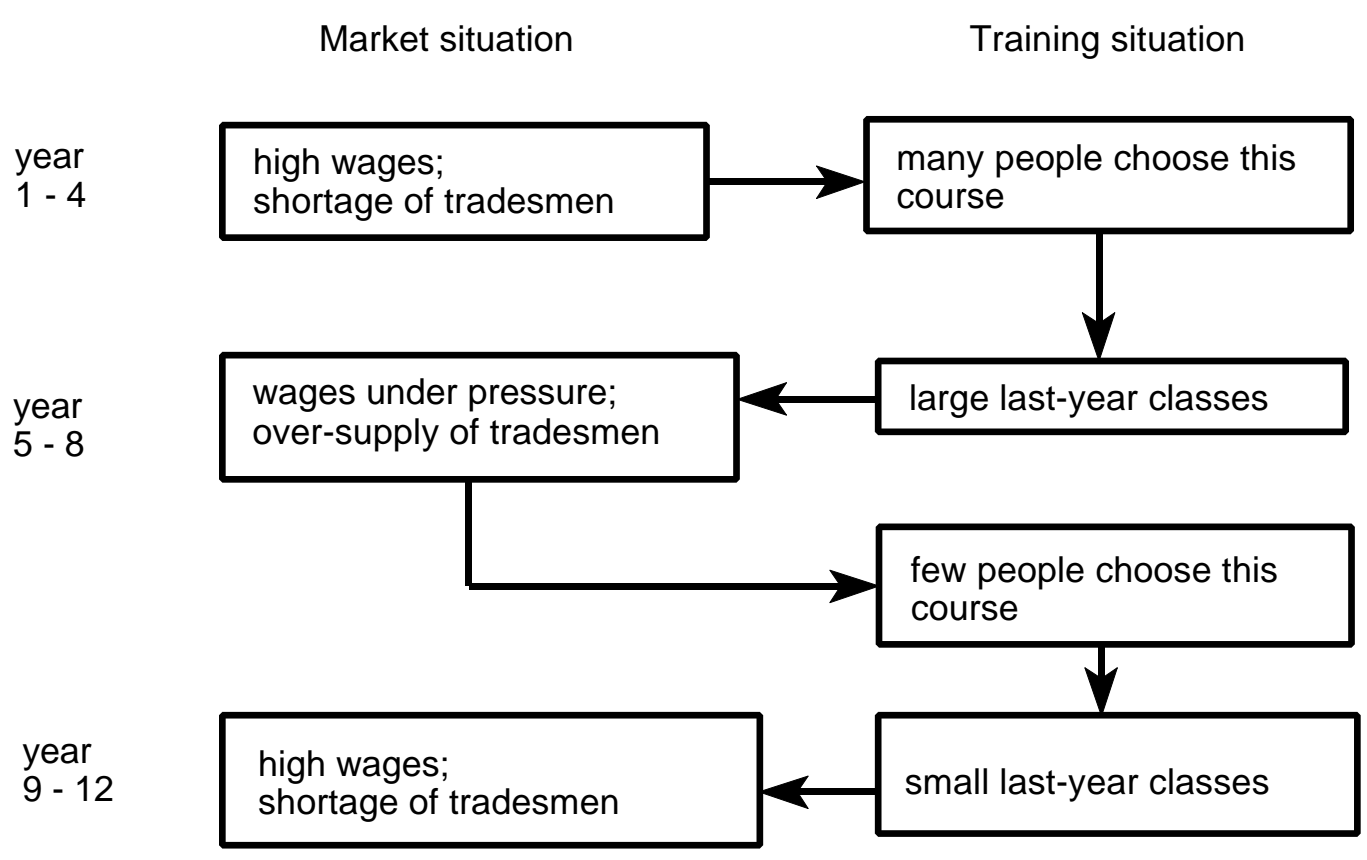

Source: de Grip (1987)

This summary of the causes implies that it should be possible to dampen the cobweb cycle oscillations by:

- making the training broader, so that a larger employment field can be commanded with that type of education. However such a broadening has to be limited if the course is to 
continue to offer a credible level of expertise in the occupation concerned. Excessively radical broadening of the training may in fact be at the price of reduced productivity in practising the occupation, so that the market value of the course is reduced;

- shortening the formal study. There are also limits to this modification. In fact, if quality is maintained by not reducing the course contents in proportion to the shorter time, less students will be able to successfully complete the course and the drop-out rate will rise;

- providing high-quality information, before students undertake the course, on the situation which may be expected in the labour market at the end of the training period. This needs to relate especially to the future level of employment in the relevant labour market segment, as compared to the expected flows coming from the education system. This solution also has its limits, since forecasts are never perfect and must generally be hedged about with generous margins for uncertainty. ${ }^{7}$

\section{ROA's labour market information system}

\subsection{Basic principles}

As mentioned in the introduction, ROA compiles forecasts of changes in the labour market in the Netherlands in the medium term at a relatively low level of aggregation (Hughes, 1993; OECD, 1994). The most recent forecast for the period 1997-2002 is broken down into 13 economic sectors, 123 occupational classes and 98 types of education.

A number of basic principles are taken into account when compiling these highly differentiated forecasts, principles which counter the more fundamental and methodological critisisms of initial manpower planning approaches. These basic principles are the following:

- The forecasts are limited to the medium term, that is, to a period of about five years. Within this horizon the changes on the labour market are less uncertain than in the long term, where the uncertain results of the emergence of substitution and other adjustment processes can be decisive, especially where the discrepancies between demand and supply may be extremely large. A forecast period of five years is moreover sufficiently long to produce useful labour market information for those who are investing in a course which will last for a number of years.

However short-term forecasts for the coming year or two-year period may be important in recruiting personnel, for short-term training courses and other short-term labour market programmes and for preparing people to enter the workforce. At present ROA does not make any short-term forecasts.

- In place of fixed coefficients for the occupational and training structure of employment,

7. For a simulation of the effects, for the labour market, of an increase in the transparency of the labour market for those choosing a course of study, see Heijke and de Grip (1995). 
explanatory models are used to describe the changes in both structures over time. This should also be attempted as regards the flows within the education system, the participation of graduates in employment and the replacement demand. The forecasting models would then be more theoretically justifiable, which would make forecasting with these models less of a black box affair.

- The theoretical framework which underlies the forecasting models incorporates both ex ante and ex post substitution processes in the forecasts of the labour market situations for the various types of education. The ex ante substitution processes refer to the demand-led substitution between types of education due, for example, to the upgrading of the skill requirements for a particular occupation, whereas ex post substitution refers to shifts in the educational structure of employment in an occupation due to the initially forecast gaps between demand and supply for the various types of education (see section 4.2).

- No detailed comparisons of demand and supply are made for each forecasting year, but the forecast itself are limited to giving a general characterization of the relation between demand and supply for broad categories of training over the whole forecast period. Information intended as guidance for students is limited to a qualitative description of the labour market prospects of these training categories, on a scale from 'good' to 'poor'. This requires that the training categories be carefully constructed, so that the variation in labour market prospects within each category is as small as possible. ${ }^{8}$ The use of qualitative descriptions will prevent the quantitative forecasts being treated as more precise than is really the case.

- The forecasts are repeated within a period of a few years. A forecast every other year makes it possible to keep a finger on the pulse, while leaving sufficient time to evaluate the observed differences between forecasts and the results realized in the market and to use these evaluations to improve the forecasting method. The differences between forecasts and realizations do have a certain tendency to increase over time. Waiting too long to make modifications will not only encourage bad decisions on training and education, the visible mistakes in forecasting will also contribute to a negative image of the value of labour market forecasts.

- It is important to make as much use as possible of any understanding which already exists of the future growth of employment and the flows from the education system onto the labour market. In the Netherlands this applies especially to changes in the employment in economic sub-sectors, which ROA takes from the Netherlands Bureau for Economic Policy Analysis, and to the flows from the education system onto the labour market, which are largely taken from forecasts made by the Ministry of Education, Culture and Science. By using these, ROA ensures that its labour market forecasts are consistent with the authoritative forecasts that provide the basis in the Netherlands for policy decisions on important social and economic issues. This results in a certain

8. For a description of the way in which ROA has defined the types of education which it differentiates, see Heijke, Matheeuwsen and Willems (1998). 
division of labour, enabling ROA to concentrate on developing its own high quality, and thus also authoritative, expertise within a fairly specialized field, in this case the match between education and the labour market. In addition to ensuring consistency with these two national forecasting activities, ROA has also sought to create a network of contacts with centres of sectoral expertise which are capable of giving high-grade information or feedback on specific elements. The elaboration and specification of these sources must of course be done in a theoretically justifiable and consistent manner.

- The uncertainties which are associated with labour market forecasts are to some extent met by mapping the labour market risks which a particular choice of training may entail, as a supplement to the forecast of the probability of finding a job. Statistical indicators are developed, for example for the opportunities which a type of education offers of switching between occupations and the sensitivity of the occupations which are relevant for a particular type of education to cyclical fluctuations.

- The forecasts made are evaluated periodically. This evaluation includes an empirical evaluation of the forecasts made by all submodels and the resulting labour market signals provided for students and firms, and a survey of the methodology, describing the strong and weak points of the models and possible improvements and extensions.

\subsection{Theoretical foundations}

A major criticism on the manpower requirements approach refers to the lack of substitution possibilities between the various groups of workers which are distinguished. In traditional manpower forecasting both ex ante and ex post substitution processes are neglected. Fixed coefficients in the models on which the employment forecasts for occupations or types of education are based neglect the effects of technological developments on the occupational structure of employment and the possible upgrading of the skill requirements for particular educational groups. For this reason explanatory variables related to these developments have been introduced in the forecasting models, although trend variables are still very important for modelling shifts in both the occupational and educational structure of employment.

The more fundamental difference of traditional manpower forecasting with neo-classical economic theory refers to the neglect of substition processes which will occur in the adjustment process of the market in case of shifts in labour supply or demand. From the very beginning ROA attempted to incorporate aspects from the labour market flexibility approach in manpower forecasting. De Grip and Heijke (1988) discuss the possibilities of combining information on the potential mobility of workers with a particular educational background to alternative occupations with the traditional point-forecasts of future employment. This can be done along two lines. First, labour market flexibility indicators can be used as additional key ratios. Second, labour market flexibility can be integrated fully in the forecasts of the future labour market prospects (Cf. Sheldon, 1985). Both lines have been followed. The first line focuses on indicators of potential labour market flexibility 
indicators, which are presented as 'risk indicators' which characterize the more or less structural aspects of the labour market position of the various types of education. These indicators will be discussed in section 5.4. The second line focuses on the incorporation of the substitution processes that could be expected in case of a gap between ex ante labour supply and demand, in the ex post demand forecasts.

The theoretical framework which underlies ROA's forecasts incorporates substitution process, and in particular these ex post substitution processes. This theoretical foundation which synthesizes neo-classical adjustment processes in the framework of manpower forecasting builds on concepts of both job matching and disequilibrium theory.

\section{Matching theory}

Van Eijs and Heijke (1996) formulated a model which focuses on the consequences of the lack of transparency of the labour market for the recruitment policy of firms. Building on matching theory, they analyse the allocation process of workers with different educational backgrounds over occupations in which different skills are required. This means that the assumption made in human capital theory that it is only the educational background of workers which determines their productivity is relaxed. An individual's productivity is related to the quality of the match between that person's educational background and the job in which he or she is employed. This quality of the match is determined by the distance between the educational background of a worker in a certain occupation and the educational background which gives the largest productivity in that occupation.

Moreover, in a nontransparent labour market workers are not necessarily perfectly allocated over the various occupations, as finding the perfectly matching worker for each job entails costs, especially if the perfectly matching worker is hard to find due to labour market tensions for this group of workers. In that case recruiting an imperfectly matching worker with an educational background for which there is excess supply could be attractive. However, recruiting an imperfectly matching worker entails training costs which will have to be met in order to bridge the gap between acquired and required skills. These training costs indicate the distance to the perfectly matching educational background for the occupation concerned. If the total of the search costs and the training costs for this worker are lower than the search costs for the perfectly matching worker, recruiting an imperfectly matching worker is the optimal policy for the firm. This implies also that to a certain degree initial education and post-initial training are assumed to be substitutes.

Job matching literature focuses particularly on the consequences of a mismatch between the acquired and required skill level, indicating undereducation or overeducation of the workers employed. Van Eijs and Heijke, however also consider mismatches related to the field of study. Moreover, they also include the degree of overeducation and undereducation in their model. They derive the indicator for the quality of the match between the 
educational background and occupation from their own modified rate of return approach. For the level of education, their reference point for undereducation or overeducation is not the educational level with the highest productivity in the occupation concerned, i.e. the level which would be a 'perfect match' for the occupation, but rather the educational level which has the highest marginal productivity in that occupation, that is, the level which would be an optimal match (analogous reasoning applies to the optimal match regarding the field of education). The educational level which is an optimal match has a comparative advantage, in that occupation, as compared to other levels of education including the educational level which would be a perfect match. This implicitly assumes that the perfectly matching level of education might be one which has a higher marginal productivity in some other occupation. The relationship between the closeness of the match between the educational level actually achieved, the level of education required in an occupation and the marginal productivity ('rate of return') is shown in figure $2 \mathrm{a}$. In this figure, the rate of return of a type of training $i$ in occupation $j\left(R_{i j}\right)$ is shown on the vertical axis, while the difference between the educational level of the person working in an occupation $\left(L V_{i}\right)$ and the educational level that yields a comparative advantage in occupation $j\left(L V_{j}^{c a}\right)$ is shown on the horizontal axis. The dotted line shows the relationship between the rate of return and the degree of undereducation $\left(L V_{i}-L V_{j}^{c a}<0\right)$ and over-education $\left(L V_{i}-L V_{j}^{c a}>0\right)$ according to traditional rate of return studies, while the continuous line shows the assumptions underlying the approach of van Eijs and Heijke.

If the individual is employed in occupation $j$, the highest rate of return $R_{j}^{c a}$ is achieved on the educational level which has a comparative advantage in occupation $j\left(L V_{i}=L V_{j}^{\text {ca }}\right)$. In the approach used by van Eijs and Heijke, the rate of return is a decreasing function of the degree of undereducation or overeducation, as indicated by the continuous lines. Moreover, the line describing the link between overeducation and the rate of return is steeper; the negative effect on the rate of return on overeducation is greater than the effect on undereducation. From the above assumptions regarding tenure-earnings profiles by occupational level and field they then derive the indicator for the quality of the match between the educational background of those working in a particular occupation and the requirements of the occupation itself. The shape of the tenure-earnings profiles they produce is shown in figure $2 b$, where the vertical axis represents the wage earned by people with the type of education $i$ in occupation $j$, while the horizontal axis represents the length of tenure, $t . W_{i j, o}$ is the initial wage and $W_{j}^{p}$ is the wage if there is a perfect match between education and occupation. The distance $W_{j}^{p}-W_{i j, o}$ can be regarded as an indicator of the degree of mismatch $M M_{i j}$. Thus the indicator in fact shows the productivity gap that must be made up by means of training and the accumulation of experience. Types of education that offer a better match with occupation $j$ will have an earnings-tenure profile lying above the profile of $i$ (a smaller $M M_{. j}$ ) while types of education that do not match that occupation so well will lie under the $i$ profile (larger $M M_{. j}$ ). 
Figure 2a

Rate of return and the degree of undereducation and overeducation

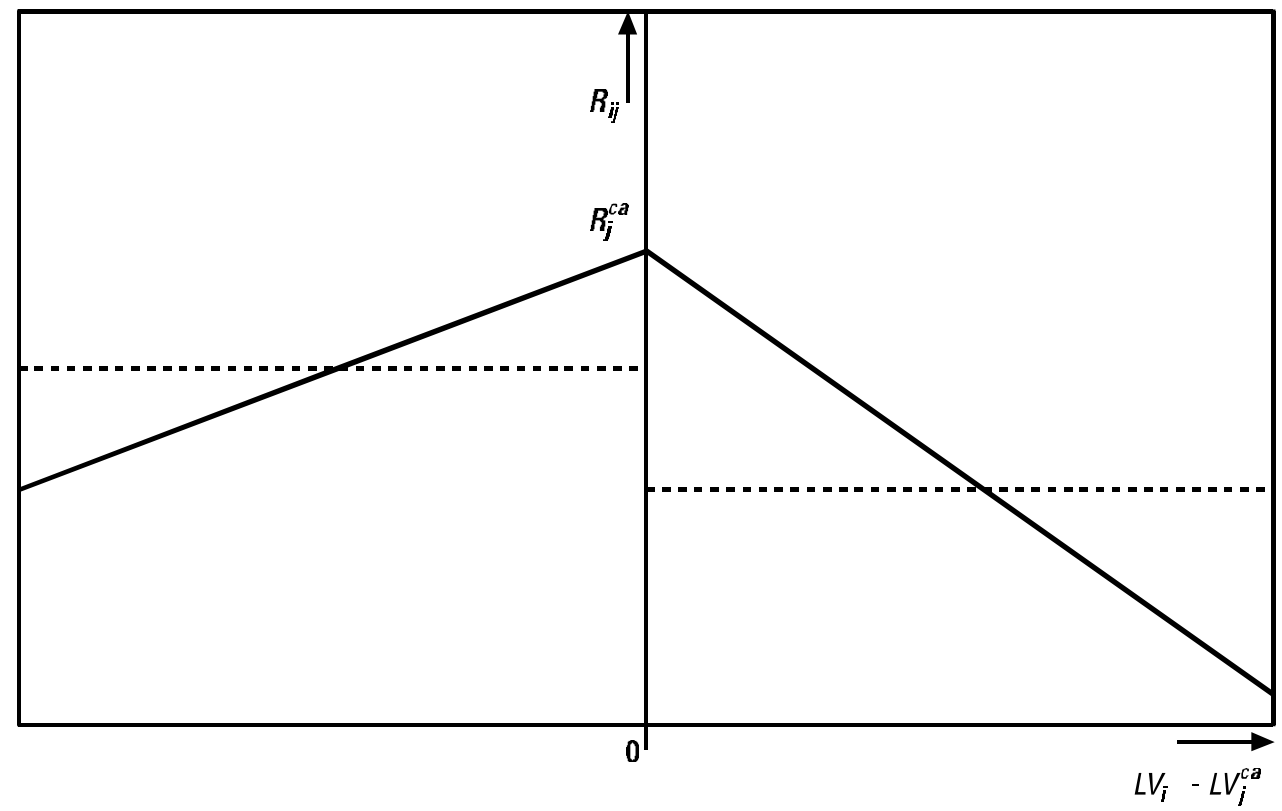

Source: van Eijs and Heijke (1996)

\section{Figuur $2 b$}

The quality of the match and the wage

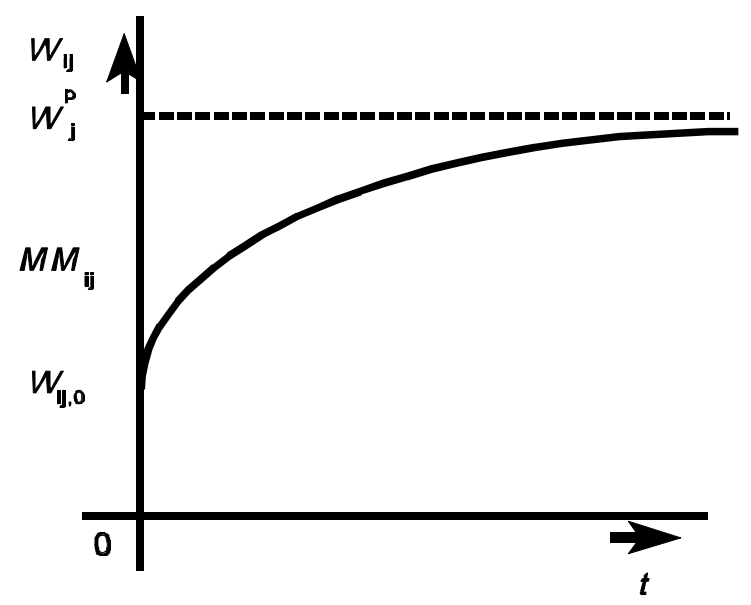

Source: van Eijs and Heijke (1996)

The approach developed by van Eijs and Heijke gives a theoretical foundation of the manpower forecasting model in which occupational employment forecasts are made first in 
the occupational model, irrespective of the allocation process on the labour market, whereas in the educational model the interaction between labour demand and supply is explicitely modelled. Implementing the approach in manpower forecasting, however, implies the availability of a data source in which individual data on the occupation, the educational background and the renumeration of workers is available in order to indicate the match between specific occupations and the types of education required, and the related distance between the relevant types of education. However no time series data is required as the parameters estimated in a cross-sectional analysis, which we may assume to be reasonably stable, can be substituted in the equations of the educational demand model, .

\section{Disequilibrium and substitution}

Borghans and Heijke (1996) develop a manpower forecasting approach which incorporates the possibility of substitution processes as an adjustment process to an ex ante disequilibrium on the labour market for a particular type of education, which can be applied in manpower forecasting at a relatively low level of aggregation. Following de Grip and Heijke (1988) they distinguish between active and passive substitution. If there is excess supply of workers with a particular educational background, some of these workers may accept a job at a lower level. These adjustments are indicated as active substitution. However, this substitution process will mean that there are fewer job openings for the types of education which suffer from this 'crowding-out' process. The latter could be characterized as the passive substitution demand.

Since the indicator which has been developed for the ex ante gaps between supply and demand aims at indicating the tensions in the labour market, possibly leading to adjustment behaviour (e.g. people accepting less favourable jobs), the employment obtained by such adjustments should not be incorporated in the comparison of supply and demand which is incorporated in the gap-indicator (for the definition of this indicator, see section 5.4). This implies that only passive substitution is incorporated in the gap-indicator. Even if the labour market was completely flexible, and all discrepancies between demand and supply were solved by wage adjustments, the gap-indicator might indicate good or bad labour market prospects. These prospects, then, indicate a discrepancy between supply and demand relative to the labour market conditions in the base year of the forecasting period. Assuming wage adjustments this would imply that a wage movement could be expected to bring supply and demand back to equilibrium. Bad prospects in that case reveal themselves as falling wages.

The way in which an ex ante supply and demand mismatch for a particular type of education may affect the occupational structure of employment for that type of education is shown in figure 3. At $t=0$, labour supply $\left(S_{o}\right)$ and demand $\left(D^{A+B}\right)$ are in equilibrium, with wage level $w_{o}$. At that moment $A_{o}$ of the workers with this particular educational background are employed in occupation $A$, in which these workers are assumed to be most productive, 
and $A_{o} B_{o}$ work in occupation $B$. If in the forecasting period labour supply decreases from $S_{o}$ to $S_{1},{ }^{9}$ ex ante forecasts will indicate a demand-supply mismatch at wage level $w_{0}$. However this gap, which is interpreted as 'good labour market prospects' for the graduates of this type of education, will increase the wage level from $w_{0}$ to $w_{1}$. Moreover, most employers who recruited workers with this educational background for occupation $B$ will no longer recruit these workers. Their wage costs exceed the benefits for the employer, who may start recruiting people with another educational background. This means that the new equilibrium the majority of the workers are employed in the occupation in which workers with this particular educational background are most productive: occupation $A$. Only a minority $\left(A_{o} B_{1}\right)$ will still be employed in occupation $B$.

Figure 3

The effects of an ex ante supply shortage on the occupational structure of employment for a particular type of education ('active substitution')

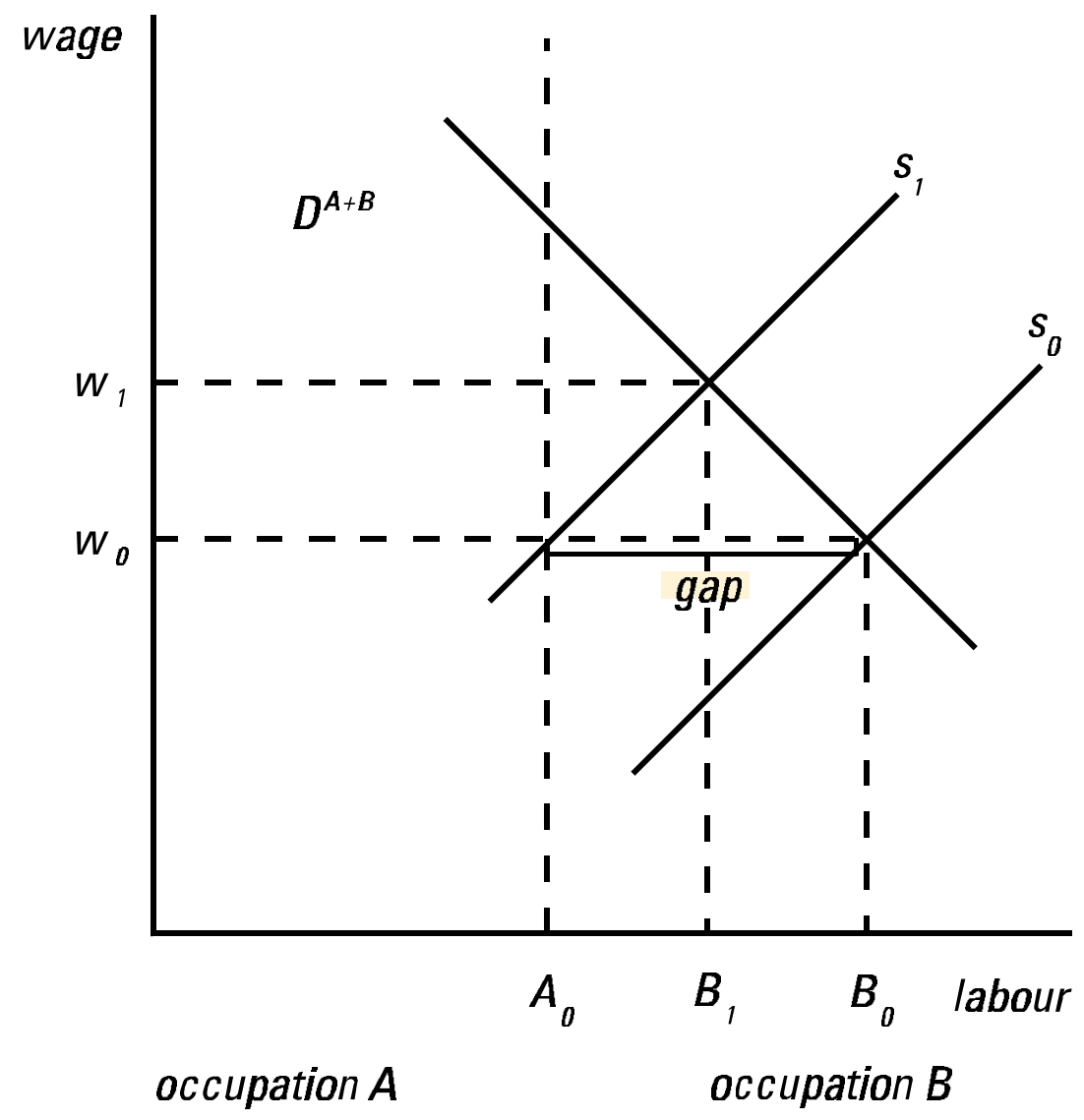

Source: de Grip et al. (1998)

Figure 4 illustrates the possible effects of passive substitution processes on the occupational structure of employment for a particular type of education. The left part of the figure

9. For convenience sake we assume that demand does not change. 
relates to type of education $i$, for which supply and demand are in ex ante equilibrium at wage level $W_{o}^{i}$. In this case the majority of the workers $\left(A_{o}\right)$ are employed in occupation $A$ and a minority $\left(A_{0} B_{1}\right)$ in occupation $B$. The right part of the figure relates to type of education $j$. Ex ante forecasts of supply and demand for this type of education indicate excess demand at wage level $W_{o}^{j}$, which is interpreted as 'good labour market prospects' for the graduates of this type of education. However, this gap will attract more workers with education $i$ to occupation $B$ jobs $\left(B_{o} B_{1}\right)$, which effects the occupational structure of employment for the latter type of education. The demand curve $D_{o}^{i}$ will shift to the right to $D_{1}^{i}$. Due to this passive substitution effect in occupation $B$, graduates from type of education $i$ will also have good labour market prospects.

Figure 4

The effects of excess demand for education $j$ on the occupational structure of employment for education $i$ ('passive substitution')

Education $i$

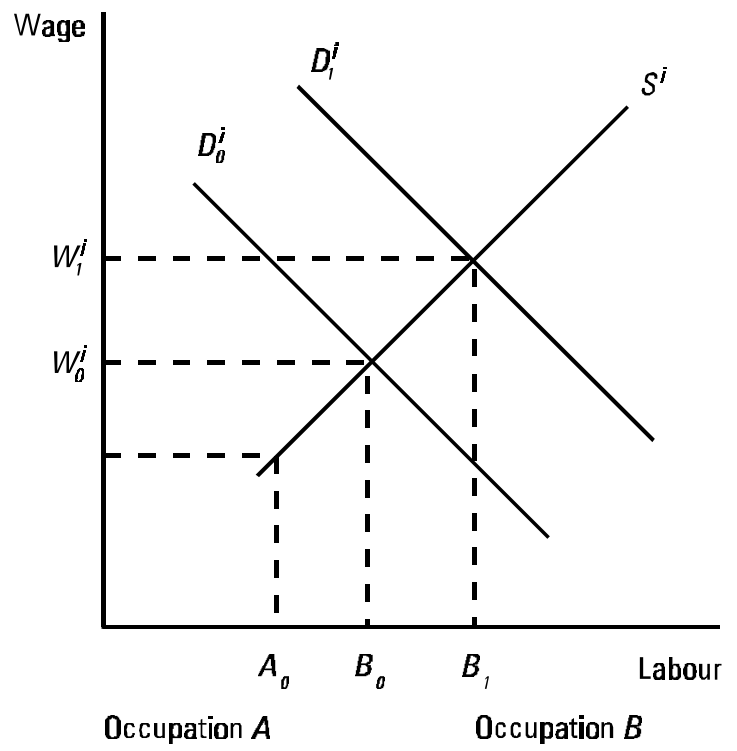

Education $j$

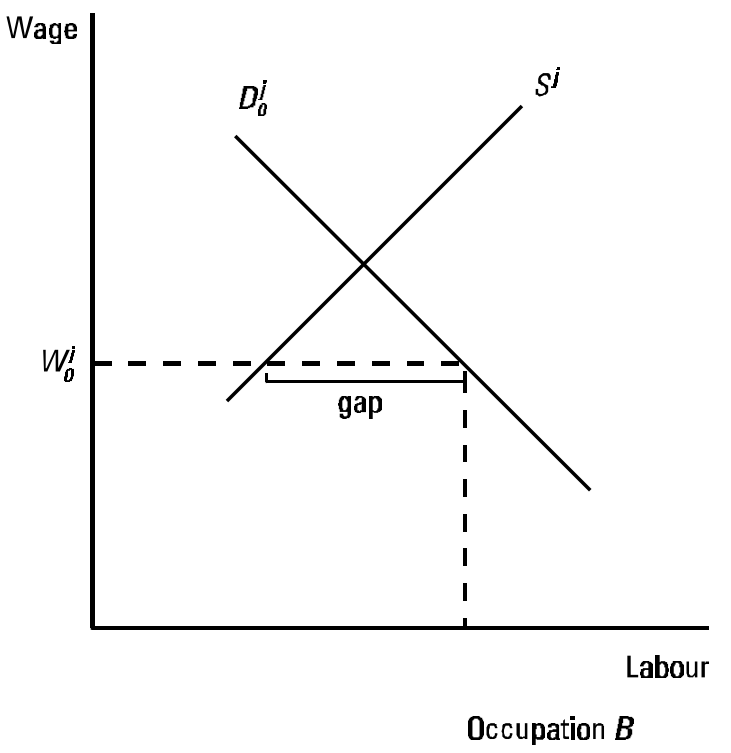

Source: de Grip et al. (1998), slightly adapted

Wieling and Borghans (1995) examine the relationship between ex ante labour demand and supply on the one hand and manifestations of these labour market tensions on the other hand. Based on data concerning the labour market position of school-leavers, they find evidence for a flexible labour market in response to supply-demand discrepancies. If supply exceeds demand, school-leavers will on average earn less, and more often find only part-time temporary jobs, below their level of education or outside their field of study. Remarkably, these authors did not find any relationship between these discrepancies and the level of unemployment. 


\subsection{General structure of the forecasting model}

Figure 5 gives a schematic overview of the forecasting model used in the information system for education and the labour market. ${ }^{10}$ One flow volume which is important for the demand side of the labour market is the expansion demand, which reflects the movement in employment levels in a particular occupational class or for a particular type of education. The forecasts of expansion demand are based on the employment level forecasts for economic sectors which are produced by the Dutch CPB Netherlands Bureau for Economic Policy Analysis. Because particular occupational classes within an economic sector grow more rapidly than others, ROA translates these changes in the economic sectors into the expansion demand per occupational class. Then the implications of the predicted growth in the various occupational classes for the expansion demand for each type of education are determined. An allowance is made at this point for any shifts which may be occurring in the educational structure of occupational classes. The expansion demand per type of education refers to the number of people with a particular educational background that employers would like to be able to employ. The actual change in employment levels per type of education will generally differ from this because changes on the supply side affect relative scarcities and lead to substitution processes.

Demand on the labour market consists not only of expansion demand, but also of replacement demand, which arises when workers retire, leave the labour force under an early retirement scheme or due to work disability, withdraw from the labour market temporarily, or switch to another occupation etc. However replacement demand only arises if the departure of an employee actually leads to a vacancy for a new entrant. If the departure of a worker is taken as an opportunity to cut employment levels, no replacement demand results. These flows out of the labour market are in fact irrelevant for newcomers.

Thus only part of the flows leaving the market generate replacement demand. Moreover, there is an important difference between the replacement demand per occupational class and per type of education, because occupational mobility has an influence on the replacement demand per occupational class, but not on the replacement demand per type of education. Switching occupations has no effect on the educational structure of employment. On the other hand, where a worker undertakes part-time study for a higher level qualification, when he or she completes that qualification it means in fact an outflow of one worker to another educational category (type of education). In that case a replacement demand does arise in the educational category under which this worker's pre vious education was counted.

If employment levels are rising, the expansion demand and replacement demand together

10. A comprehensive explanation can be found in Borghans et al. (1997). See also de Grip et al. (1995). 
comprise the job openings for newcomers to the labour market. If employment levels are declining job openings can only arise due to replacement demand.

In the labour market, the total demand for newcomers confronts the expected supply of newcomers. The latter consists of the future flow of school-leavers entering the labour market and the outflow from training courses after and outside the regular education system during the forecast period, plus the supply of short-term unemployed persons waiting to enter the market at the start of this period. It is assumed that the long-term unemployed, who have been looking for work for longer than a year, no longer constitute serious competition for school-leavers.

The forecasts of the flows of school-leavers entering the labour market correspond to the Referentieramingen 1997 (Reference forecasts 1997) which are compiled by the Ministry of Education, Culture and Science for courses in the 'regular' (i.e., full-time initial) education system. ROA disaggregates these forecasts, and supplementary data is used to estimate the effects of the flows from non-regular education on the educational makeup of the flows entering the labour market.

An indication of the future labour market prospects for newcomers to the labour market is derived, for each type of education, by confronting the expected flows of demand and supply with each other. This indicator shows what discrepancy may be expected between the demand and supply for each type of education. But, as mentioned in section 4.2, excess supply does not imply that the group in question will as a matter of course become unemployed, and a supply shortfall does not automatically mean that there will be unfilled vacancies. In practice, it appears that school-leavers with a type of education for which the supply exceeds demand do suffer from a deterioration of their position, for example because they are more likely to have to accept work below their level, get less favourable contracts, are less well paid or more likely to work part-time involuntarily (Wieling and Borghans, 1995). In such a situation, employers would normally modify their demands and recruit people with a higher educational background than was originally contemplated. On the other hand, if there is a supply shortage the position of school-leavers will improve, and they will then not have to accept a job at a lower level, for lower wages, etc.

Because of substitution processes, there will be fewer job openings for those with the types of education which suffer from 'crowding-out' by types of education with an excess supply. On the other hand, for those with educational backgrounds which are closely related to types of education which are in short supply, there will be extra job openings. These passive substitution effects are thus important determinants of the labour market prospects of types of education.

The confrontation between demand and supply also gives an indication of the future risk of labour recruitment problems for each type of education. The expansion and replacement 
demand jointly determine the recruitment requirement for each type of education. If employment for a particular type of education is declining, this recruitment requirement is calculated in a somewhat different manner than the number of job openings for newcomers to the labour market, because from the employers' point of view it is possible to achieve part of the retrenchment by limiting their recruitment, so that fewer of the existing personnel have to be dismissed. Employers will be especially likely to use this option when they face a tight labour market for a particular type of education.

\section{Figure 5}

General structure of the forecasting model for ROA's information system for education and the labour market

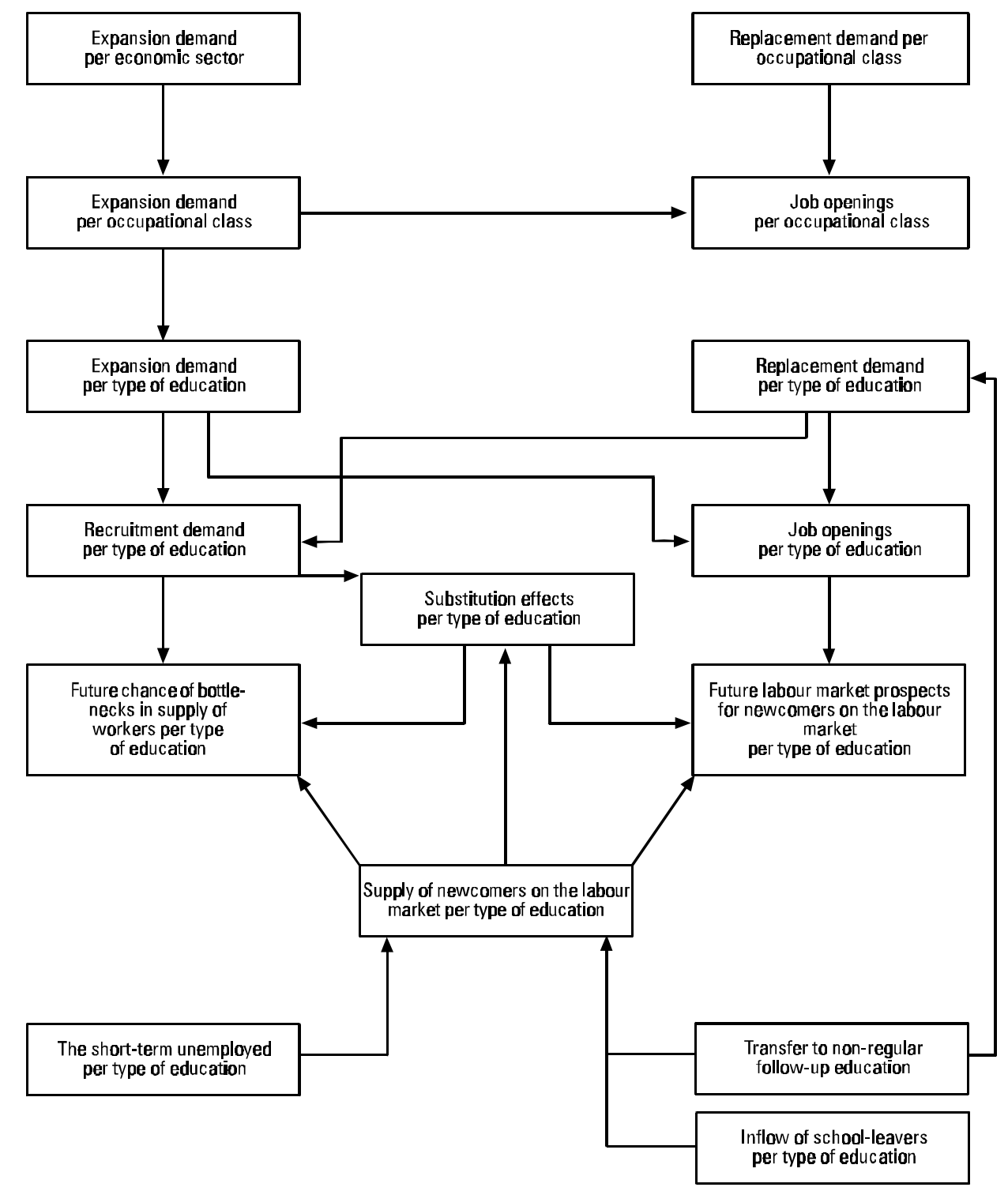

Source: ROA (1997) 


\subsection{Occupational and educational classification}

A crucial factor for the quality and usefulness of the labour market forecasts is that occupational and educational classifications used match as much as possible the labour market segments as they exist in practice. The (international) occupational and educational classifications used in most countries are based on adminstrative criteria. Sanderson (1987) points at the fact that administrative occupational groupings are often inappropriate for studies including occupationally disaggregated manpower. Of course, the same holds for adminstrative educational groupings. As a matter of fact the early manpower planning studies (e.g. Parnes, 1962) already pointed out the importance of good classification systems for occupational groups and educational categories, as it is important that highly substitutable categories are combined in groupings for which forecasts are made. In de Grip et al. (1991) a cluster analysis is performed in order to define clusters of occupational groups according to their educational structure. This clustering procedure combines occupations that have very much the same distribution of the total employment in the occupation over types of education. The underlying assumption is that such groups with similar schooling profiles belong to the same labour-market segment and therefore offer opportunities for good forecasts of labour demand by occupational group, since developments will probably be more similar in homogeneous occupational groups.

For the educational classification the argument is even stronger, as in the information system the confrontation between the labour demand and labour supply forecasts is made by type of education. As administrative educational classifications reflect the formal structure of the educational system they do not indicate the real differences in competencies that people have obtained during their education to fulfil their jobs in the labour market. On the one hand there are labour market segments with very strict educational requirements ('craft markets'). Examples are the labour market segments for doctors, lawyers, accountants, etcetera. On the other hand, however, in many segments of the labour market a large extent of educational flexibility can be observed and no one-toone relationships between education and the labour market exists (Sheldon, 1985; de Grip and Heijke, 1988). It might be clear that for a confrontation of labour demand and labour supply forecasts by educational category, it will be fruitful to use an educational classification that takes into account the actual segmentation of the labour market. For types of education which largely operate in the same labour market segment it is incorrect to regard the developments of supply and demand separately, as the substitution between these types of education will be very high in practice. A shortage of the one group will almost automatically lead to an increasing demand for the other group.

In the Standaard Beroepenclassificatie '92 Statistics Netherlands builds on the philosophy developed in de Grip et al. (1991). The various occupational groups distinguished are as homogeneous as possible with respect to the educational requirements in the jobs. Based on this occupational classification - which is compatible with the International Standard 
Classification of Occupations 1988 (ISCO '98) the labour market system of the ROA distinguishes altogether 127 occupational groups at five different job levels ranging from elementary occupations to scientific occupations.

The educational classification used in the information system is developed in Heijke et al. (forthcoming). The classification is based on the observed substitution possibilities of workers with different educational backgrounds within the same jobs. These substitution possibilities implicitly indicate the overlapping skills of workers that have attended different courses. Borghans (1992) and van der Velden and Borghans, 1993) introduced a similarity or competition index which measures the prevailing substitution possibilities between different educational types.

This similarity index $s$ is defined as:

$$
s_{i, i^{\prime}}=\frac{\sum_{j}\left(\frac{p_{i, j}}{\sum_{j} p_{i, j}}\right)\left(\frac{p_{i^{\prime}, j}}{\sum_{j} p_{i^{\prime}, j}}\right)}{\sqrt{\sum_{j}\left(\frac{p_{i, j}}{\sum_{j} p_{i, j}}\right)^{2} \sum_{j}\left(\frac{p_{i^{\prime}, j}}{\sum_{j} p_{i^{\prime}, j}}\right)^{2}}}
$$

where:

$p_{i j} \quad=$ the number of people with an education of category $i$ working in occupational category $j$.

$s_{i, i^{\prime}}=$ similarity index of educational category $i$ with educational category $i^{\prime}$.

This similarity index $s_{i, i^{\prime}}$ is equal to 0 (no similarity) if both types of education $i$ and $i^{\prime}$ have no overlapping occupations. It is equal to 1 (perfect similarity) if and only if the occupational structure of both educational types is completely equal in the sense that the relative numbers of workers in each occupation is equal for these two educational types. If in total $I$ number of educational types are distinguished, a $I x I$ matrix $S$ of similarity indexes can be specified. Obviously the similarity of a type of education with itself $\left(s_{i, i}\right)$ is equal to 1 and the similarity index is symmetric $\left(s_{i, i^{\prime}}=s_{i^{\prime}, i}\right)$. This implies that one can distinguish $I(I-1) / 2$ similarity indexes. In Heijke et al. (1998), the new educational classification is obtained by using cluster analysis to combine educational categories that are very similar to one another. ${ }^{11}$

Starting point of the cluster analysis is the very detailed 5-digit classification of the Standaard Onderwijs Indeling (SOI) of Statistics Netherlands. At this level approximately

11. This classification is compatable with the International Standard Classification of Education (ISCED) 
800 educational types are distinguished. Based on the substitution possibilities between these educational types within 320 occupational categories an educational classification is derrived in which altogether 113 types of education are distinguished. ${ }^{12}$

\section{Labour demand and supply submodels}

\subsection{Expansion and substitution demand forecasts}

The expansion demand forecasts are probably the most difficult element of ROA's information system on education and the labour market. Figure 6 gives an overview of the structure of the ROA employment forecasts. In contrast to the traditional manpowerrequirements approach, no fixed relations between occupations and types of education are assumed. As in some earlier studies by ROA, a somewhat more flexible relationship is assumed based on explanatory variables for the changes in both the occupational and educational structures of employment.

The employment projections by sector which are made by the CPB Netherlands Bureau for Economic Policy Analysis with the help of their Athena model are the starting point for the forecasts. This means that the more detailed forecasts, which distinguish the prospects of particular types of education and occupations, are consistent with the broadly accepted macro-economic and economic sector forecasts of the CPB.

The Athena model of the CPB is a multi-sector model of the Dutch economy which distinguishes 14 sectors (CPB, 1990). For each sector a clay-clay production function with heterogeneous vintages (annual cohorts) is used. Disequilibrium may arise in the production process and the labour market, which then feeds back into prices, wage rates, investment, the demand for labour, etc. The employment equation for the industrial sectors is derived from the model for production capacity and consists of three parts: one part describing the vintage effect on labour volume, one part describing the 'disembodied' changes in the number of jobs and one part describing short-term adaptation processes. The employment level equations for the remaining economic sectors are not derived from a formal production function but were formulated ad hoc on the basis of studies of each sector.

12. Apart from the substitution criterion some additional criteria are used: (1) a minimum number of workers of 5,000 for each type of education distinguished for reasons of statistical reliability, (2) the classification has to be recognizable for its users (e.g. clusters that cover more formal levels of education are splited up. 
Starting from the CPB forecasts of employment by sector, a two-step model is estimated to explain the occupational structure of the sectors. The changes in employment levels per economic sector are first translated into employment changes per occupational segment. Then the forecast of expansion demand is further disaggregated by occupational classes. The assumption in the design of the occupational models is that the occupational structure of a sector is entirely determined by the demand side of the labour market. Changes in the demand per occupational class are determined by shifts in employment between economic sectors and changes in the occupational structure of the employment per economic sector.

Figure 6

Structure of the expansion demand forecasts

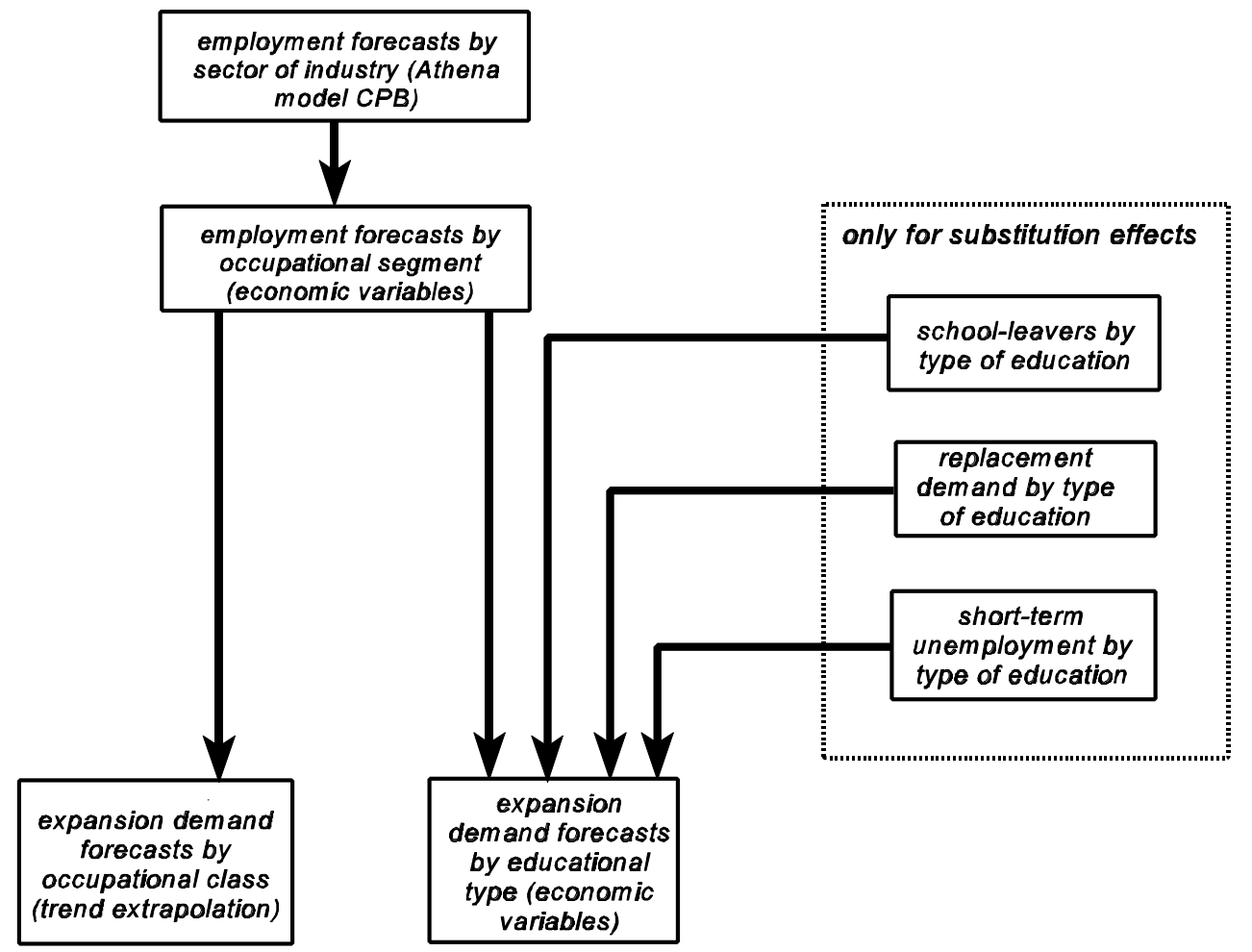

Source: de Grip et al. (1995)

Changes in the employment structure are estimated on the basis of the Labour Force Survey data from 1981-1996. In accordance with the new definition of the working population, this data relates to people working at least 12 hours per week. Because the available time series is rather short, in earlier versions of the occupational model it proved difficult to get reliable parameter estimates which would indicate reasonably stable future developments.

In order to get more reliable parameter estimates without affecting the specificity of the 
separate occupations, a random coefficients model has been used. ${ }^{13}$ In this random coefficient model each parameter value is a weighted average of the average parameter value over all the pooled occupations on the one hand and estimates for each separate occupation on the other hand. The weighting is determined by the accuracy of the two components. If there is a great deal of variation between the various occupations, a pooled estimate is relatively inaccurate and more weight is placed on the separate estimates. However if these separate estimates have a high standard error, their weighting is reduced. Thus an optimal combination is found between the information in the pooled data and in the separate estimates.

There have been changes not only in the estimation techniques, as compared to the approach used in earlier versions of the information system (see Dekker et al., 1990), but also in the specification of the equation. A specification which forecast employment levels has now been replaced with one which forecasts growth. In the earlier method, a regression equation was estimated on the basis of the shares of particular occupations in employment in each economic sector. If, in the most recent year for which observations were available, this share was much larger or smaller than in the previous years, this was implicitly treated as an anomaly. But by forecasting growth, the implicit assumption is that these unexplained changes in employment levels will continue in the future. However, because an explanatory model of the occupational structure will always be insufficient, it is better to treat such anomalous results as an indication of unexplained changes which will continue to have their effects in the future.

For each economic sector, the following specification is taken as a starting point:

$$
\dot{a}^{o s}=\dot{a}^{s}+\beta_{1}^{o s} t+\beta_{2}^{o s} \dot{Y}^{s}+\beta_{3}^{o s} H O \dot{U} R+\beta_{4}^{o s} \dot{U} R+\epsilon^{o s}
$$

where:

$\dot{a}^{\text {os }} \quad=$ the growth rate of occupation $o$ in economic sector $s$;

$\dot{a}^{s} \quad=$ the rate of growth in the total number of people working in economic sector $s$.

$t=$ the number of years between two successive observations. The parameter value of $t$ thus indicates the constant growth rate per year.

$\dot{Y} \quad=$ growth in the capacity of production. In the industrial economic sectors this is determined by calculating how many labour years of labour input would be required if the present physical capacity was fully utilized (i.e., current employment divided by the utilization ratio $\left.\left(\dot{y}^{*}\right)\right)$. For the other sectors this definition is replaced with the gross added value at factor costs (for the construction industry, domestic deliveries excluding imports), $\dot{y}$.

$H O \dot{U} R=$ the growth in the hours per year worked under employment contracts.

13. Borghans and Heijke (1994) provide a detailed description of this model. 
UR $=$ the unemployment rate.

It is assumed that the vector $\beta^{o s}=\left(\beta_{1}^{o s}, \ldots, \beta_{4}^{o s}\right)$ is normally distributed:

$\beta^{o s} \sim N\left(0, \Sigma^{s}\right)$

Each parameter is thus specific for each occupation $(o)$ in each economic sector $(s)$ but, because of the random coefficient structure (5.2), there is a reciprocal link between the parameters of the various occupations in the same economic sector. However, not every explanatory variable is used in every economic sector. The explanatory variables correspond to those used in the Athena model of the CPB. Table 1 shows which explanatory variables are used for each economic sector. Relative wage costs are not included in the model, for lack of adequate data. Consequently, it is assumed that the wage structure as such does not change, or that the influence of the wage structure on the occupational structure of employment within economic sectors is constant.

Because the method described above led in some instances to implausible results, some ad hoc modifications have been made to this general structure. The first modification is for the sector 'Other commercial services', which includes both the banks and insurance companies and other commercial services. The result is that this economic sector is rather heterogenous. In the past the banks and insurance companies have experienced strong growth, which implies that the occupational segments which are linked to these economic sectors have also enjoyed strong growth. In the estimates this is expressed in high parameter values for the trend variable for these occupational segments. This growth would therefore also be forecast for the coming years, but the CPB, in its more specific sector forecasts, expected a reduction in the employment growth in the banking and insurance sector. The methodology which has been used would mean that retrenchment in the economic sector, which is caused by the banks and insurance companies, would affect all occupational segments, and moreover that the shares of the occupational segments which are most strongly represented in banking and insurance would increase because of their past growth. In order to prevent implausible results for the economic sector 'Other commercial services', the constant term here is replaced, as a trend variable, by the growth and forecast growth for the banking and insurance sector. The result is that the occupational segments which have enjoyed strong growth in the past, presumably due to the growth of these business, are forecast to suffer greater cuts than the other occupational segments in coming years.

A second modification to the general method described above relates to the occupational segment 'Government, police, defense and education'. Since the government as a whole will, according to the CPB, suffer retrenchment, this would also apply to police numbers. But in fact the government has excluded any cuts in these occupational groups. Therefore the number of people working for the government in this occupational segment has been 
assumed to be constant.

Because of the conservative character of the forecasting technique which has been used, it did not appear necessary to make more ad hoc modifications. It would appear very important that, in the future, solutions should be found for the high heterogeneity of the economic sector 'Other commercial services', in particular. Separating out the banks and insurance companies would, in this respect, be a marked improvement.

The forecasts of expansion demand per occupational segment are further dissagregated to forecasts per occupational class. This takes place in a model with a structure similar to that of the model for occupational segments. The difference between the growth of an occupational class and growth in the occupational segment is estimated, with the constant term as the only explanatory variable for growth. This estimation also employs a random coefficient model.

Table 1

Overview of the explanatory variables per economic sector

economic sector

explanatory variables used

$t \quad \dot{y}^{*} \quad \dot{y} \quad H O U R \quad$ UR

Agriculture, fisheries and forestry

Food and beverages industry

Chemicals

Metal, electrical, and transport requirements industries

Other industry

Energy

Construction

Commerce

Transport and communication

Other commercial services

Non-commercial services

Government, police, defense and education
$\mathrm{X}$

$\begin{array}{lll}x & x & x\end{array}$

$\begin{array}{lll}x & x & x \\ x & x\end{array}$

$\begin{array}{lll}x & x & x \\ x & x\end{array}$

$\begin{array}{lll}x & x & x \\ x & x\end{array}$

$\begin{array}{lll}x & x \\ x & x\end{array}$

$\begin{array}{lll}x & x & x\end{array}$

$\begin{array}{lll}x & x \\ x & x\end{array}$

$\begin{array}{lll}x & x \\ x & x\end{array}$

$x \quad x \quad x$

$\mathrm{X} \quad \mathrm{X}$

The educational demand model

In earlier versions of the forecast model of the information system, the forecasts of the expansion demand per type of education were derived from the occupational forecasts in a way analogous to the occupational model (see Beekman et al., 1991). The assumption that the demand for labour per occupational segment is independent of supply factors is reasonably plausible, but at the level of types of education allowance must be made for the fact that the actual employment per type of education depends on supply factors. 
For instance, in a labour market with high unemployment the competition for jobs may be such that more highly qualified workers displace the less skilled from their 'occupational territory'. The result of this 'crowding-out' (see Teulings and Koopmanschap, 1989) is that persons with a high level of education occupy jobs previously held by persons with a lower level of education. Consequently discrepancies arise between the ex ante demand per type of education before the demand has adjusted to the supply and the ex post demand for labour, after these adjustments. The ex ante demand is most suitable for ascertaining the tension which may be expected between demand and supply. The adjustments which take place later will in fact be an expression of these tensions between demand and supply. However, it is the ex post demand which is observed in the data.

Economists may prefer the classical or neo-classical procedure, by which the phenomenon of displacement is described with the help of the relative scarcity of a certain level of education as expressed in relative wages. However, for lack of adequate information about the wages earned by persons with a given education, it is necessary to resort to an approximation for the influence of wage factors.

By basing the historical demand in the educational model on actual employment levels, any demand and supply factors are incorporated. This would mean that an increase in employment as the result of an increased supply could be interpreted as an increase in the ex ante demand. This would lead to an under-estimation of the tension between demand and supply. To avoid this confusion between demand and supply factors, a model has been developed in which the distinction between the ex ante and ex post demand for labour is explicitly taken into account (see Borghans and Heijke, 1996). To enable these two separate categories to be identified, allowance is made in this model for mutual substitution between types of education.

Figure 7 shows the construction of the educational model. The ex ante demand per type of education $(e)$ and per occupational segment $(0)$ is determined by the distribution of the types of education in this occupational segment in the most recent year for which observations are available. Because of downward displacement and concentration around the average training level, the ratios between the shares of the various types of education in an occupational segment shift as follows:

$\bar{a}_{o e}=a_{o e}^{t-1} e^{\left(-\gamma_{1}\left(6-l_{e}\right)\right)} e^{\left.\left(-\left.v_{2}\right|_{e}-l_{o}^{t-1}\right)\right)}$

where:

$\bar{a}_{o e}=$ number of people with education $e$ in occupation $o$ according to the adjusted training structure;

$a_{o e}^{t-1}=$ number of people with education $e$ in occupation $o$ in the base year $t-1$; 
$l_{e}=$ the level of education $e$ (2 for primary education to 6 for academic education);

$I_{0}^{t-1}=$ the average level of the types of education in occupation 0 in the base year $t-1$;

$\mathrm{Y}_{1}=$ coefficient indicated the extent of downward displacement in a 5-year period;

$\mathrm{V}_{2}=$ coefficient indicating the average degree of concentration for a 5-year period.

If the supply of a type of education is greater than the demand, the labour market position of that type of education will, according to this model, deteriorate. As a result, newcomers on the labour market will have to switch to other jobs and accept less attractive jobs. The assumption is that the degree of switching to other jobs is proportional to the job structure of this type of education in the previous period. Because the total demand per occupational segment is assumed to be constant, flows of people with one type of education into the labour market automatically mean that other types of education will be displaced. Once again it is assumed that these outflows are proportional to the training structure of this occupational segment. But this displacement means an increase in the discrepancy between demand and supply for the types of training concerned. By reiterating this process a number of times an equilibrium situation is found, indicating the ex ante demand with substitution.

Figure 7

Components of the demand for labour per type of education

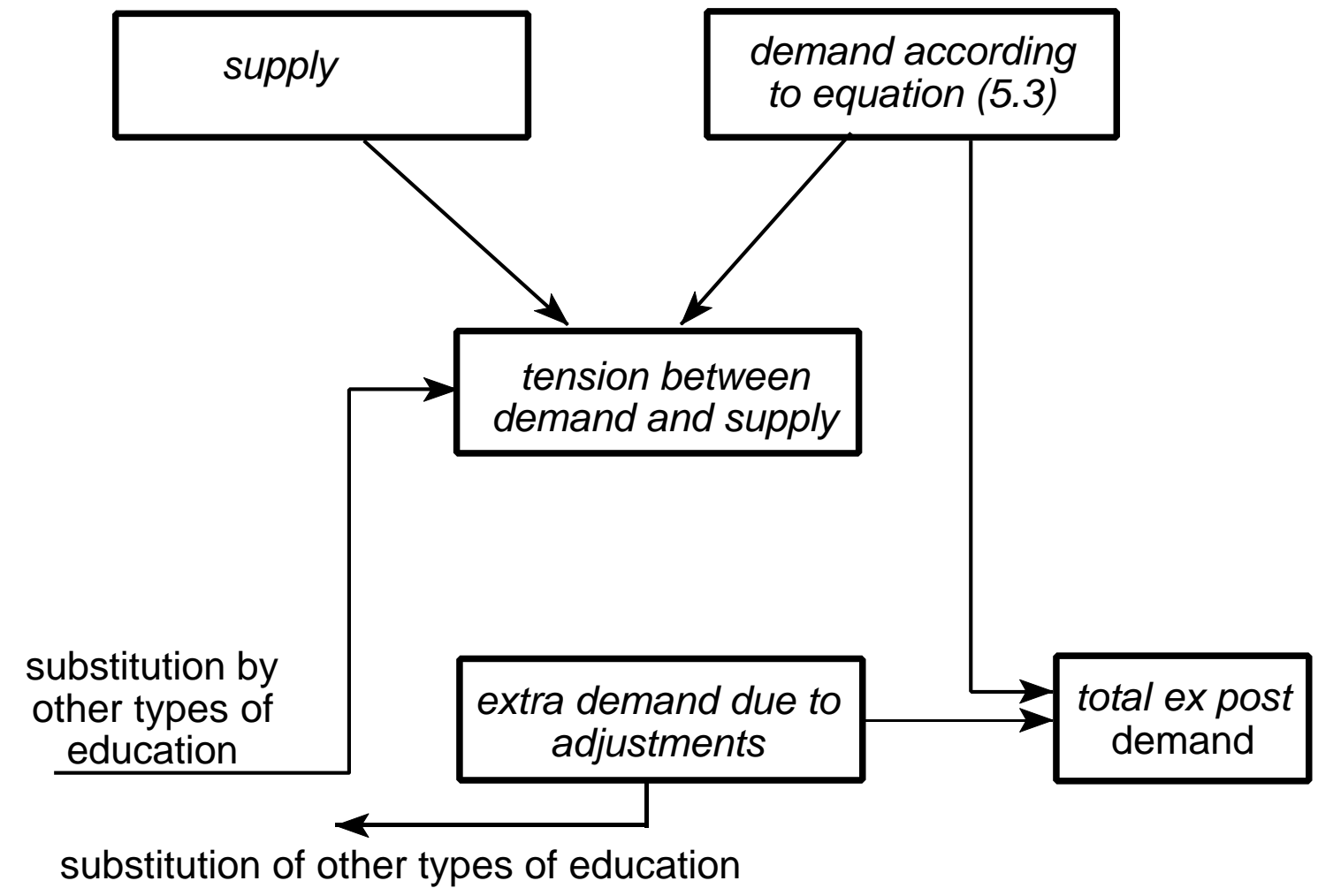

Source: de Grip et al. (1995) 
This expansion demand with substitution indicates how great the demand for schoolleavers with a given educational background is, if no allowance is made for the extent to which people with this type of education adjust to the labour market situation, but allowance is made for the increase or decrease in demand as a result of displacement by other types of education. The reason for this is that adjustments made by people with a particular type of education would in themselves already indicate a worsening in their situation (at least, in the event of an excess of supply). If the post-adjustment employment level is subtracted from the excessive supply, these worsened prospects would be under-estimated. But the reduction in employment opportunities as a result of adjustments made by people with other types of education does mean that employment possibilities are worse, so this component must be incorporated in the ex ante demand.

ROA's forecasting model distinguishes the various processes which determine future employment for particular types of education. First, changes in labour demand in an economic sector affect employment for the skill categories employed in that sector. In addition to this industry effect, there will also be different changes in the employment levels for the various occupational classes within a single economic sector. This occupational effect is due to some extent to the heterogeneity of the economic sectors as these are defined, but also to changes in the activities within an economic sector. Moreover, the skills which are demanded in these occupations also change. Because of these changes, some types of education which are better adapted to the developments in the demand for qualifications will show a positive education effect. These three effects combined represent the total expansion demand for a particular type of education. As a result of discrepancies between labour demand ${ }^{14}$ and supply there are, inevitably, additional shifts in demand as employers adjust their desires in accordance with the availability of workers. The latter effect is designated the substitution effect. As described above we can differentiate here between active substitution, resulting from supply-demand mismatches for the type of education concerned, and passive substitution due to spill-over effects from supplydemand mismatches for other types of education.

The model structure distinguishes between the 'demand led' changes in skill requirements on the one hand and the substitution or 'crowding out' effects relating to labour market mismatches on the other hand. The first three effects indicate the 'demand led' changes in the skill requirements due to shifts in the industry structure, the occupational structure and the skills required in the various occupations, respectively. The latter two effects indicate the substitution processes due to labour market mismatches.

14. This demand refers to both expansion and replacement demand (see figure 5). 


\subsection{Replacement demand forecasts}

Replacement demand is an important component of the future demand for newcomers on the labour market (see de Grip et al., 1994). It can be the result of permanent departures from the labour force due to retirement, early retirement, and other temporary withdrawals such as married women stopping work due to birth and child-rearing, etc. Replacement demand for a particular occupational category can also be due to occupational mobility. As in the previous section, we will describe the methodology used, first in the forecasts of replacement demand by occupational class and then by type of education.

\section{Occupational classes}

Figure 8 is an input-output table for the entire population, in which these mobility processes are schematically reproduced at an aggregated level (see also Willems and de Grip, 1993). The inner part of the input-output table contains the mobility flows within the labour market. Some of these flows are indicated by the capital letters $A$ to $G$. 'Flow' $A$, indicates the number of employees who continued to work in occupation 1 during the period $(t-n, t)$. Flows $B$ and $E$ represent job-to-job mobility. Flows $C$ and $D$ represent departures from employment, to unemployment and non-availability respectively. The latter indicates changes such as retirement and voluntary exit, particularly of married women. The unemployed who have found a job during the period $(t-n, t)$ are indicated by the letter $F$. Finally, flow $G$ refers to new positions gained by those who were not available for the labour market at time $t-n$, such as school-leavers who find a job and women who re-enter the labour market.

The replacement demand should be defined in relation to expansion demand. Where there is an increase in employment, the replacement demand is equal to the number of workers who leave a certain job during the period $(t-n, t)$. The vacancies that thus appear will have to be filled before there can be a rise in the total numbers employed. If there is a decrease in employment, not all of the vacancies created by departing employees are filled. The replacement demand is then not equal to the total number of departures from a certain job, but rather to the number of vacancies that are actually refilled, that is, the total inflow of labour to the job in question. The concept of replacement demand can be explained further using figure 8. If there is an increase in employment, the replacement demand for occupation 1 is equal to the sum of the flows $B, C$ and $D$ (the total outflow). However, if employment in occupation 1 decreases, the sum of flows $E, F$ and $G$ (the total inflow) gives the replacement demand.

The first step in modelling future replacement demand per occupational class is a description of the inflow and outflow patterns by occupational class in a historical period. Because there is no appropriate data for mobility flows on the labour market, stock data is used. By means of the so-called cohort components method we calculate cohort-change 
rates based on the number of persons of the same birth cohort who were employed at two different times (see Shryock and Siegel, 1980). These cohort-change rates can be rewritten as average annual net inflow or outflow percentages. ${ }^{15}$

$$
{ }_{k} \dot{F}_{o, a}^{t-1}=\frac{{ }_{k} W_{o, a+1}^{t}-{ }_{k} W_{o, a}^{t-1}}{{ }_{k} W_{o, a}^{t-1}}
$$

${ }_{k} \dot{F}_{o, a}^{t-1}=$ the annual net inflow or outflow ratio of workers in occupational class 0 of age group a (with class width $k$ ) at time $t-1$ during the period $(t-1, t)$;

${ }_{k} W_{o, a}^{t}=$ the number of people working in occupational class 0 of age group $a$ (with class width $k$ ) at time $t$.

If $\dot{F}^{t-1}>0$ there is a net outflow for a certain age group from an occupational class, and if $\dot{F}^{t-1}<0$ there is a net inflow.

Figure 8

Input-output table of labour market flows

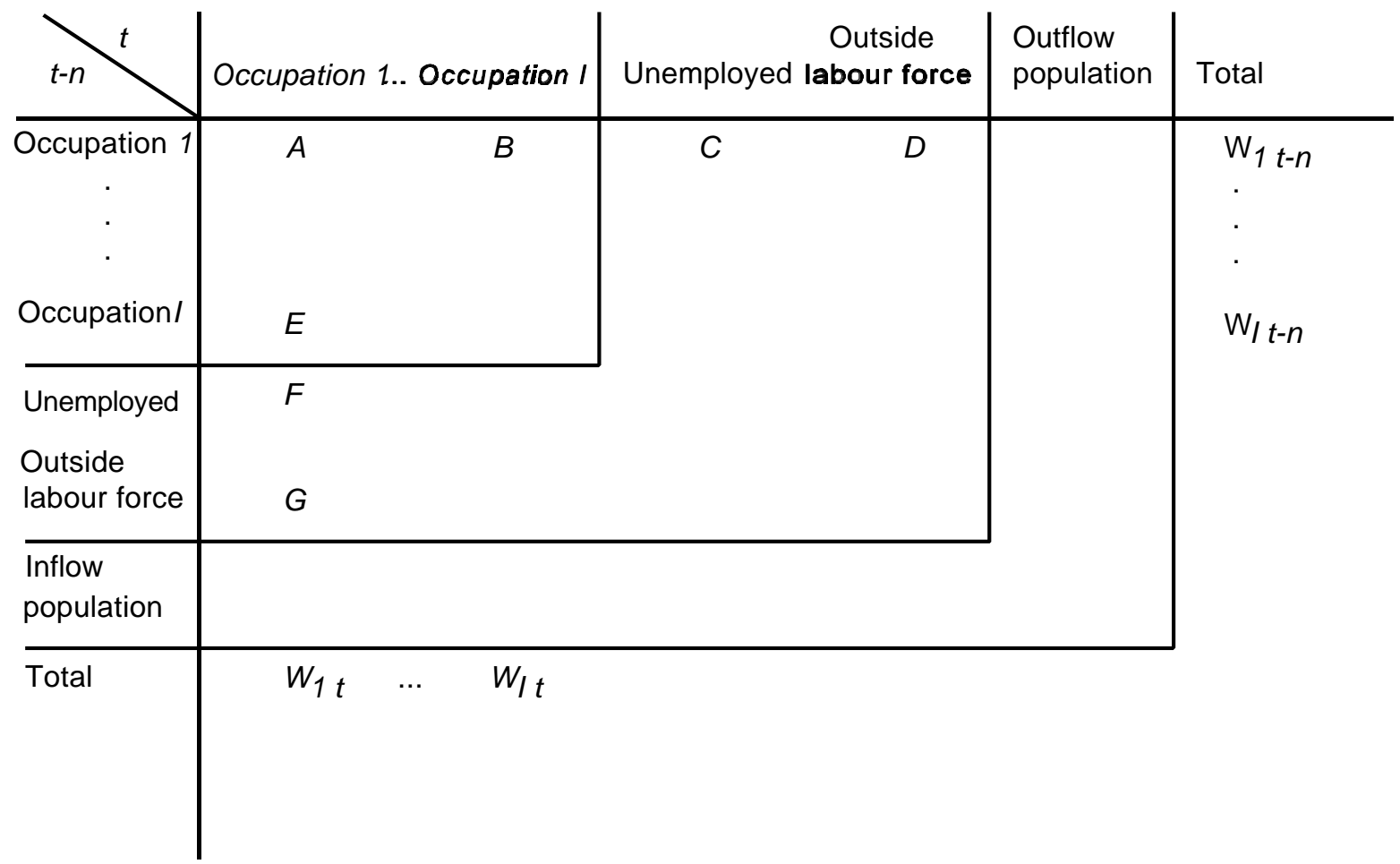

Source: Willems and de Grip, 1993

15. Flow rates for male and female workers are differentiated. 
The second step in modelling is to translate these inflow and outflow percentages into the replacement demand by occupational class. As stated above, for occupational classes with an increase in employment in the period $(t-1, t)$, replacement demand is equal to total net outflow in this period. However, for occupational classes which faced a decrease in employment, not all vacancies due to the outflow of workers will have been filled. Therefore replacement demand for these occupational classes equals the number of vacancies that were actually refilled, that is, the total inflow of workers in the occupational class. In this way the more or less 'structural' replacement demand is derived.

This methodology measures only the net flow to or from an occupational class. This means that replacement demand satisfied by re-entering workers of the same age cohort is not measured. So replacement demand is actually measured for newcomers on the labour market. However, this is exactly what is intended, in as much as ROA information system focuses on the prospects for newcomers on the labour market.

A random coefficient model is then estimated in which the net inflow or outflow ratios are explained on the basis of the average inflow or outflow from the total working population on the one hand and the occupation-specific deviations per age-sex group on the other. This approach guarantees that the sum of the net flows among the occupations corresponds to the total inflow or outflow.

Written mathematically:

$$
\dot{F}_{o}=\dot{F}+\Sigma_{x} \beta_{o x} D_{x}
$$

Where:

$\dot{F}_{o}=$ vector of net inflow of outflow ratios for occupation 0 , with observations per sex, age group and year;

$\dot{F} \quad=$ the same, but then for the total working population;

$D_{x}=$ matrix with dummy variables; elements are equal to 1 for cohort $x$ and 0 elsewhere;

$\beta_{o x}=$ random parameters.

The third step is to project the historically measured net replacement demand rates per age-sex group for a particular occupational class onto the age-sex structure of the workers at the beginning of the forecasting period. Moreover, the historically observed cohort change rates are corrected for business cycle effects and for expected changes in participation rates. For more details see Willems and de Grip (1993).

The business cycle correction is equal to the difference between the change in the total number of working persons and the change in the labour force in the historical period. This correction offsets the outflow of workers who become unemployed due to cyclical fluctuations in employment levels. The correction for changes in the participation rate is the 
difference between the growth in the labour force in the historical and the forecasting period. Both correction factors are sex and age specific.

If the cyclical correction and the participation rate correction are combined, the forecast future outflow ratio by age category will be:

$$
\begin{aligned}
{ }_{k} \dot{W}_{o, a}^{t, m} & ={ }_{k} \dot{W}_{o, a}^{t, n}+{ }_{k} L \dot{F}_{a}^{t, n}-{ }_{k} \dot{W} P_{a}^{t, n}+{ }_{k} \dot{L} \dot{F}_{a}^{t, m}-{ }_{k} \dot{L} \dot{F}_{a}^{t, n} \\
& ={ }_{k} \dot{W}_{o, a}^{t, n}-{ }_{k} \dot{W} P_{a}^{t, n}+{ }_{k} \dot{L} \dot{F}_{a}^{t, m}
\end{aligned}
$$

where:

${ }_{k} \dot{W}_{o, a}^{t, m}=$ the expected average annual net inflow or outflow ratio of workers in occupational class $O$ of age group a (with class-width $k$ ) at time $t$ during the forecast period $(t$, $t+m)$;

${ }_{k} \dot{L} \dot{F}_{a}^{t, n}=\quad$ the average annual growth ratio of the total labour force of age group a (with class-width $k$ ) at time $t$ - $n$ during the period $(t-n, t)$;

${ }_{k} L \dot{F}_{a}^{t, m}=$ the expected average annual growth ratio of the total labour force of age group $a$ (with class-width $k$ ) at time $t$ during the forecast period $(t, t+m)$;

${ }_{k} \dot{W} P_{a}^{t, n}=$ the average annual rate of growth of the total number of working persons of age group $a$ (with class-width $k$ ) at time $t-n$ during the period $(t-n, t)$.

Future replacement demand is further determined in the same way as historical replacement demand. That means that for occupational classes with an expected increase in employment, replacement demand equals net outflow. For occupational classes for which a decrease in employment is expected, replacement demand is equal to the total net inflow.

In compiling the forecasts for the period 1997-2002 it was possible to use data differentiated by sex and age category for the number of workers per occupational class, and per type of education, for the years 1990-1996. On the basis of the data, the cohort change rates were determined. By applying a random coefficients model, which incorporates the total labour market outflow, one obtains the expected net labour turnover coefficients for the forecast period, on the basis of which the replacement demand can be determined.

\section{Types of education}

Replacement demand by type of education must be interpreted differently from replacement demand by occupational class, as net mobility between occupational classes must also be taken into account in the latter. However, when a worker with a certain educational background changes occupation, this does not create a vacancy for a 
newcomer on the labour market with the same educational background. Therefore this does not influence replacement demand for newcomers for the type of education in question.

There is another difference between the replacement demand by occupational class and by type of education. If someone leaves a certain occupational class and is replaced by an employee with another (e.g. higher) educational background, there is a replacement demand for the occupational class in question. When such displacement or substitution effects occur, however, there is no question of replacement demand for the type of education in question, but rather of an employment decrease for one type of education and an employment increase for the other. However, this relation between expansion demand and replacement demand is not explicitly taken into account in the expansion demand forecasts. Moreover, one could ask whether the replacement demand model should incorporate the forecast negative expansion demand, instead of the historical development of employment.

\subsection{Forecasts of inflow of school-leavers}

For each type of education, forecasts have been made of the potential flow of schoolleavers onto the labour market. Several data sources have been used for these forecasts. The Ministry of Education and Sciences makes annual forecasts of the number of schoolleavers from full-time and part-time education. These so-called 'Reference forecasts' are differentiated by sex and age, but they are at a higher level of aggregation than ROA's categorization of types of education (Ministerie van Onderwijs, Cultuur en Wetenschappen, 1997).

The forecasting model used is based on a transition-matrix based on the composition of full-time education and a classification of the population by level of education. Flow coefficients relate the 'origin' of students in year $t$ to the 'destination' of these students in year $t+1$. By means of these flow coefficients, future numbers of students from each educational category can, step-by-step, be forecast. However, such a straightforward approach would suppose that students' choices remain unchanged during the entire forecasting period. Therefore, the flow coefficients of students who get a certain qualification are considered as strategic flow coefficients. These strategic flow coefficients are the dynamic elements of the model as they are determined by (modified) trend extrapolations.

As the Ministry's forecasts of school-leavers are at a higher level of aggregation with regard to the types of education, distribution keys are needed to break down these forecasts. These distribution keys are formulated from various additional data sources.

Besides those leaving school with a qualification, the Reference forecasts cover students 
who end their studies without a diploma. With the help of the education matrix for 1995 , these school-leavers can be re-assigned to any preliminary course from which they had obtained a diploma.

A forecast is also made of the flow from non-regular education (apprenticeships, recognized correspondence courses, training in medical care etc.) onto the labour market. Data about that category has to be taken from available additional statistics, or obtained directly from the training institutions concerned. However enrolment in non-regular courses changes the qualification profile of 'school-leavers'. For that reason, the number of students who have successfully completed such courses has to be proportionally subtracted from their preliminary regular educational groups. Another correction is needed to prevent students enroling in several non-regular courses or in a regular and non-regular course of the same type being counted twice. In this way a forecast can be drawn up of the flow from both regular and non-regular educational groups onto the labour market. ${ }^{16}$

\subsection{Labour market indicators}

This section will discuss the various indicators which are central in ROA's 'labour market information system'. The information system combines labour market forecasts with 'risk indicators' which indicate the more or less structural aspects of the labour market position of the various types of education. First, the indicators of the future labour market prospects for newcomers on the labour market and the indicators of future recruitment problems are discussed. These two indicators represent the expected labour market situation from the point of view of the supply and demand sides, respectively. Secondly, the 'risk indicator' with respect to the cyclical sensitivity of employment and the possibility of lateral mobility are presented.

By matching labour demand with labour supply, an indicator of the future labour market situation (IFLM) can be constructed. This indicator of labour market prospects is constructed for each of the types of education which are distinguished. As explained above, labour demand is the sum of the (positive) expansion demand, replacement demand and the passive substitution demand due to excess demand or supply for closely related types of education. Labour supply consists on the one hand of the expected inflow in the period 1997-2002 and on the other hand of the number of unemployed with the same educational background who had been unemployed for less than one year in 1997 . The exclusion of those unemployed for more than one year is based on the supposition that they do not compete on the labour market with school-leavers with the same type of education.

In formulaic form, the indicator for a specific type of education is as follows:

16. See Berendsen et al. (1992) for detailed information about the method and the required data. 


$$
I F L M_{e}=\frac{E_{e 97}+I N S_{e 97-02}+U_{e 97}}{E_{e 97}+\max \left(0, E D_{e 97-02}\right)+R D_{e 97-02}+S D_{e 97-02}}
$$

where:

$$
\begin{aligned}
E_{e 97}= & \text { employment in type of education e in } 1997 \\
I N S_{e 97-02}= & \text { forecast influx of school-leavers with educational background } e \text { during the } \\
& \text { period 1997-2002 } \\
= & \text { number of people with educational background } e \text { that are less than one year } \\
U_{e 97} & \text { unemployed in } 1997 \\
E D_{e 97-02}= & \text { forecast expansion demand for type of education e during the period 1997- } \\
& 2002 \\
R D_{e 97-02}= & \text { forecast replacement demand for type of education e during the period 1997- } \\
& 2002 \\
S D_{e 97-02=}= & \text { forecast substitution demand for type of education } e \text { due to supply-demand } \\
& \text { mismatches for other types of education }
\end{aligned}
$$

The indicator of the future labour market situation is translated into a 'qualitative characterization' of the expected labour market prospects on a 5-point scale: very good, good, reasonable, moderate and poor prospects, respectively. Such a qualitative characterization in quite broad terms suffices for various purposes, including vocational and educational guidance counselling. Moreover, it prevents too much significance being attached to the exact numbers produced by the equation, which also increases the reliability of the forecasts.

Apart from the expected labour market situation for newcomers, the expected recruitment problems for firms are also dealt with. The indicator for this is, in principle, the mirror image of the IFLM. However when there is a reduction in employment for a particular type of education, the total demand ('recruitment need') is not calculated in the same way as the number of vacancies for newcomers on the labour market, because from the point of view of businesses it is possible to achieve part of the required reduction by further restricting the inflow, so that fewer of the current staff have to be dismissed. Business will certainly use this possibility when they are confronted with a tight labour market for a particular type of education. For the rest, the indicator of future recruitment problems (IFRP) is equal to the IFLM.

$$
I F R P_{e}=\frac{E_{e 97}+I N S_{e 97-02}+U_{e 97}}{E_{e 97}+E D_{e 97-02}+R D_{e 97-02}+S D_{e 97}}
$$


However, an unfavourable labour market indicator does not automatically mean that school-leavers will be confronted with unemployment, any more than a clear demand surplus will automatically lead to unfilled vacancies. The final consequences of a demand or supply surplus depend also on the market position of a particular type of education and occupational class, for instance on whether school-leavers can switch to other sectors of the labour market or on the substitution possibilities between the types of education within an occupational class.

Therefore, in addition to the labour market forecasts, two risk indicators are included in the information system. These risk indicators give an indication of the cyclical sensitivity of employment in a certain occupational class and of the possibilities of switching to another occupation (lateral mobility) or another economic sector (inter-sectoral mobility), indicating the labour market flexibility of the educational type concerned. The trend in the dispersion index is also entered into the information system.

The cyclical sensitivity of occupations is measured as follows (See de Grip and Heijke, 1988). For every economic sector the following fluctuation index is calculated:

$$
F l_{s}=\frac{100}{H} \sum_{t=1}^{H} \frac{\left|F_{s t}\right|}{T_{s}}
$$

$\mathrm{Fl}_{s}=$ cyclical sensitivity index for sector $s$;

$F_{s t}=$ divergence of employment in sector $s$ and year $t$ from the trend value;

$T_{s}=$ trend value of employment for sector $s$;

$H=$ number of observation years.

The trend values are determined by taking the five-year moving average of employment in the sector, over the period 1954-1994.

Supposing that employment in the various occupations within an occupational class fluctuates to the same degree as the total employment in the economic sector, a fluctuation index for each occupation may be derived by weighting the fluctuation-indices of the various sectors by the sector share in the occupational class.

$$
\begin{aligned}
& F I_{o}=\sum_{s=1}^{S} \alpha_{o s} F I_{s} \\
& F I_{o}=\quad \text { cyclical sensitivity index for occupation } o ; \\
& \alpha_{o s}=\quad \text { sector share in occupation } o ; \\
& S=\text { number of sectors. }
\end{aligned}
$$

The possibility of lateral mobility for people with a given education to other occupations is 
calculated by means of the 'Gini-Hirschman' coefficient, as follows (See de Grip and Heijke 1988):

$$
\begin{aligned}
& \left.G H_{e}=1-\sum_{o=1}^{O} \beta_{e o}^{2}\right) \frac{o}{O-1} \\
& G H_{e}=\text { dispersion index of educational type e; } \\
& \beta_{e o}=\text { portion of occupational group o in educational type } e ; \\
& o \quad=\text { number of occupational groups. }
\end{aligned}
$$

This indicator can have values between 0 and 1 . The value is 0 if the type of education is found in only one occupation, and 1 if people with that type of education are dispersed equally over all occupations. In determining the indicators, only those who are actually working in an occupational group at a level corresponding to their education or a higher level are considered.

These risk indicators are a very important addition to the labour market forecasts. For example, high occupational dispersion will make medium to long-term forecasts rather conditional, because, in the event of excess supply, it would be expected to be relatively easy for those in this educational group to shift to other segments of the labour market. The cyclical sensitivity indicator may also relativize medium to long term forecasts. If high employment growth is forecast for an occupational class with high cyclical sensitivity, the possibility has to be taken into account that this growth could be sharply reduced in the longer term, or even that it could turn into a decrease in employment.

\section{Employment forecasts by educational levels}

Table 2 gives an overview of the types of education for which the largest expansion demand is expected in the period 1997-2002, in relative terms. The table also gives a general characterization of the relative expansion demand. As mentioned in section 4.1, these qualitative descriptions of the forecasts, are intended to communicate the forecasting results in a more reliable way than presenting point-estimates, which are often treated as more precise than is really the case. ${ }^{17}$

All the types of education with a 'relatively strong' expansion demand are expected to have an expansion demand of $5 \%$ or more per year. Almost all these types of education relate to people with higher education. The highest expected demand is for the type of education UE, Information science. ${ }^{18}$ The trend to the computerization of work has already led to a

17. The five classes of characterization are determined by means of a symmetric demarcation based on the average workers and the standard deviation of the various forecasts (see Wieling et al., 1990).

18. The abbreviated educational levels - PVE, IVE, HVE and UE - are explained at the foot of table 2. 
very high demand for people with this educational background in the period 1992-1996 and especially at the end of that period. In fact one could say that the growth was declining, although the annual expansion demand in the coming years will continue to be at a very high level, of almost $10 \%$. Much of this high expansion demand is the result of the increasing demand in the IT occupations for people with an education in IT at university level and the fact that there are at present few people in this group. However a high expansion demand is also expected for those with an education in IT at the HVE level. It is also striking that this list of the most rapidly growing types of education includes as many as four types of education at the tertiary level which are linked to economics and commerce - UE, Management science; UE, Economics and econometrics; UE, Accountancy and taxation and HVE, Commerce. Especially in the case of the university courses, much of the high or very high expansion demand is the result of a shift in the training requirements in the occupational groups in which people with this educational background are employed.

Table 2

Types of education with the highest relative expansion demand 1997-2002 (total numbers and average annual percentage) and 1992-1996 (average annual percentage)

Type of education

forecast 1997-2002

number $\%$ char. $\%$ char.

\begin{tabular}{lrll} 
UE, Information science & 4,700 & 9.8 & very high \\
UE, Management science & 10,300 & 8.3 & very high \\
UE, Economics and econometrics & 15,900 & 6.6 & very high \\
UE, Accountancy and taxation & 6,700 & 6.4 & very high \\
HVE, Agriculture and animal husbandry & 2,900 & 6.1 & very high \\
PVE, Security & 4,000 & 6.1 & very high \\
HVE, Communication and journalism & 5,300 & 5.8 & very high \\
UE, Architecture & & 3,000 & 5.7 \\
$\quad$ very low & & & \\
HVE, Law and public administration & 6,900 & 5.6 & high \\
HVE, Commerce & 12,000 & 5.2 & high \\
IVE, Pharmacist's assistant & 4,800 & 5.1 & high \\
HVE, Information science & 10,200 & 5.0 & high \\
& & & \\
\hline PVE = Preparatory Vocational Education & & \\
IVE = Intermediate Vocational Education (includes apprenticeships) \\
HVE = Higher Vocational Education \\
UE = University Education
\end{tabular}

Source : ROA

However the expansion demand for these higher economic types of education is also declining in comparison to the situation in past years. Considering developments in the agricultural sector, it is striking that a very high expansion demand is expected for HVE, Agriculture and animal husbandry. At first glance this is inconsistent with the low predicted 
expansion demand for skilled agricultural workers and for agricultural managers. However few of those with an educational background in HVE, Agriculture and animal husbandry are in fact working in these occupations: most of the people working in these occupations have an education at the IVE level. This list of types of education which are growing strongly includes only one type of education at the lower level: PVE, Security. The very high expansion demand for this type of education is largely the result of the upgrading of the training requirements for security functions. However the expansion demand for this type of education has again declined in comparison with recent years. The one type of education at the intermediate level in this table is IVE, Pharmacist's assistant, for which the growth in employment seen in past years is expected to continue. In contrast, UE, Architecture is an example of a striking reversal in the trend in expansion demand. Where the demand declined in recent years by an average of $5 \%$ per year, in the coming years an annual expansion demand of $5 \%$ is expected. Much of this growth is attributable to increasing employment in the occupational group of civil engineers.

Table 3

Types of education with the lowest relative expansion demand 1997-2002 (total numbers and average annual percentage) and 1992-1996 (average annual percentage)

\begin{tabular}{|c|c|c|c|c|c|}
\hline \multirow[t]{2}{*}{ Type of education } & \multicolumn{3}{|c|}{ forecast 1997-2002 } & \multicolumn{2}{|c|}{ 1992-1996 } \\
\hline & number & $\%$ & char. & $\%$ & char. \\
\hline PVE, Printing trades & $-1,000$ & -3.8 & very low & -12.9 & very low \\
\hline Primary education & $-80,400$ & -3.6 & very low & -3.1 & very low \\
\hline PVE, Agriculture & $-12,700$ & -3.6 & very low & -4.7 & very low \\
\hline UE, Theology & -900 & -3.2 & very low & -10.7 & very low \\
\hline PVE, Bakery & $-1,700$ & -2.7 & very low & -8.9 & very low \\
\hline PVE, Admin., commerce and textiles & $-15,300$ & -2.7 & very low & -3.3 & very low \\
\hline PVE, Automobile trades & $-4,700$ & -2.4 & very low & -6.1 & very low \\
\hline HVE, Teacher training, languages & $-3,200$ & -2.2 & very low & -2.8 & very low \\
\hline PVE, Mechanical trades & $-11,100$ & -2.0 & low & -3.9 & very low \\
\hline IVE, Aviation technology & -600 & -2.0 & low & -10.3 & very low \\
\hline PVE, Nursing & $-3,000$ & -1.7 & low & -4.6 & very low \\
\hline PVE, Precision engineering & -400 & -1.6 & low & -14.7 & very low \\
\hline
\end{tabular}

Abbreviations: see Table 2

Source : ROA

As table 3 shows, the lower types of education are over-represented among the types of education with the most rapidly declining demand. However this represents a striking contrast to the list of the most rapidly declining occupational groups. For all the lower types of education, declining employment opportunities are entirely or almost entirely due to upgrading of the training requirements in the occupations in which those with these educational backgrounds have traditionally found work. The demand for those with PVE, Printing trades is expected to decline most rapidly, although this decrease in the demand is much less rapid than in recent years. In absolute terms, the largest decrease in the 
demand over the five-year period is for workers with only primary education, a decline of more than 80,000 workers. This decline is purely the result of the increasing training requirements in the occupations in which people without educational qualifications work. At the level of Intermediate Vocational Education (including apprenticeship) declining demand is expected for IVE, Insurance industry and IVE, Aviation technology. However the decline in demand, especially for the training in aviation technology, is much less than in the past years, when the effects of the Fokker bankruptcy were being felt. Only two types of higher education, UE, Theology and HVE, Teacher training, languages are present in this list of types of education for which the demand is declining. In both cases the expected decline in demand is a continuation of the fall in the past period, although in the case of UE, Theology the decline in demand has been considerably reduced.

Table 4 shows the extent to which the demand for labour by educational level will change as a result of the economic sector, occupational, educational and substitution effects in the coming five years. These changes in employment levels refer to the net effects per educational level, so that the positive and negative shifts experienced by the various types of education within the same level cancel each other out.

Over the period 1997-2002, a total increase in employment levels of $8.8 \%$ is expected. However if the various educational levels are differentiated, great differences within the total change in employment levels become clearly evident. For primary education, a marked decrease in the expansion demand, of more than $17 \%$, is expected. This contrasts to the situation at the university level, where there is a rise of almost $25 \%$. In fact the higher the educational level, the greater the expected expansion demand is.

Table 4

Components of the changes in employment by educational level (net-effects), 1997-2002*

\begin{tabular}{|c|c|c|c|c|c|}
\hline Educational level & $\begin{array}{l}\text { economic sector } \\
\text { effect } \\
\%\end{array}$ & $\begin{array}{l}\text { occupational } \\
\text { effect } \\
\%\end{array}$ & $\begin{array}{l}\text { educational } \\
\text { effect } \\
\%\end{array}$ & $\begin{array}{l}\text { passive } \\
\text { substitution } \\
\%\end{array}$ & $\begin{array}{l}\text { total } \\
\%\end{array}$ \\
\hline Primary education & 9.3 & -2.7 & -24.5 & 0.3 & -17.6 \\
\hline PVE, LGSE & 9.1 & -2.6 & -7.4 & -3.9 & -4.8 \\
\hline IVE, HGSE & 9.0 & 0.8 & 4.7 & -0.7 & 13.8 \\
\hline HVE & 8.2 & 0.7 & 7.0 & 1.1 & 17.1 \\
\hline UE & 9.0 & 3.4 & 7.3 & 5.0 & 24.6 \\
\hline Total & 8.8 & $0.0^{* *}$ & $0.0^{* *}$ & $0.0^{\star *}$ & 8.8 \\
\hline $\begin{array}{l}\text { PVE }=\text { Preparat } \\
\text { LGSE }=\text { Lower G } \\
\text { IVE }=\text { Intermed } \\
\text { HGSE }=\text { Higher G } \\
\text { HVE }=\text { Higher V }\end{array}$ & $\begin{array}{l}\text { ocational Educatic } \\
\text { al Secondary Educ } \\
\text { Vocational Educati } \\
\text { al Secondary Educ } \\
\text { onal Education }\end{array}$ & $\begin{array}{l}\text { ation } \\
\text { on (includes a) } \\
\text { cation (includes }\end{array}$ & $\begin{array}{l}\text { renticeships) } \\
\text { Pre-university }\end{array}$ & Iucation) & \\
\hline
\end{tabular}


$\mathrm{UE} \quad=$ University Education

* $\quad$ the percentages in this table relate to the whole period 1997-2002.

** the totals of the occupational effect, the educational effect and the substitution effect is zero in every case, because these figures refer to shifts in employment shares. Thus a positive occupational effect at one educational level necessarily implies a negative effect Source : ROA on another level.

On the basis of the growth of the various economic sectors in which workers with a particular educational background find employment, a growth in the demand might be expected at all educational levels. This economic sector effect is greatest for primary education since people with only primary education are strongly represented in the most strongly growing economic sectors: hotel and catering, repair services and business services, commerce, metalworking and electrical engineering and transport and communication. However for this sector effect the differences between the educational levels are very small.

The occupational effect, which results from changes in the spread of the employment in each economic sector over occupational classes, is not very large for any educational level. It is negative for the lowest two educational levels and positive for the others. People with lower education thus suffer relatively more from shifts in the occupational structure within the economic sectors. Those with university education profit the most from this effect.

It can also be seen that there is a shift in the level of the qualifications which are demanded. However the educational effect is smaller at lower educational levels. The figures for the educational effect point in the same direction as the occupational effect, but are much greater. People without educational qualifications suffer most from the increase in the educational requirements set by employers. People with an education at university level, and to a slightly lesser degree at an HVE level, benefit the most.

Where there are differences between demand and supply, both those offering labour and those seeking workers will adjust their demands. People who are seeking work and are confronted with a lack of job openings within the field in which they have trained will then be more likely to accept a function at a lower level or in another field. This is known as active substitution. Employers will also hire people with another type of education or educational level if they have difficulties in filling vacancies. In that case the substitution is passive.

The latter substitution effect is expected to be negative for the educational levels of PVE and LGSE, for Intermediate Vocational Education, and for HGSE. The negative passive substitution for people with Preparatory Vocational Education or Lower General Secondary Education in part indicates that they can be replaced by people who have only primary education. In contrast, those with an education at the level of Intermediate Vocational Education or Higher General Secondary Education are faced with being crowded out by 
people with Higher Vocational Education. The UE level profits the most from the extra demand resulting from the inadequate supply of graduates from related fields of study. 


\section{Students' prospects and recruitment problems up to 2002}

\subsection{Labour market prospects for school-leavers}

As figure 5 shows, it is possible to give an indication of the expected labour market prospects for newcomers to the labour market, differentiated by type of education, on the basis of the predicted changes in demand and supply on the labour market. The conclusions on this point are based on the Indicator of Future Labour Market prospects (IFLM) for each type of education, which reflects the relationship between the supply of labour with that educational background and the corresponding demand (see equation 5.7). If the supply of labour is smaller than the demand, and the IFLM is thus less than 1.00, the labour market is characterized as good. If the value of the IFLM is even below 0.85 , this is characterized as very good labour market prospects. On the other hand, if the IFLM lies between 1.00 and 1.05 so that the excess supply is not much greater than the level attributable to labour market friction, this is characterized as reasonable labour market prospects. For higher values of the IFLM the labour market prospects for that type of education are characterized as moderate or, if the IFLM exceeds 1.15, as bad.

\section{Types of education with very good prospects}

The relatively favourable labour market developments expected for the period 1997-2002 mean that many types of education are expected to enjoy favourable to very favourable labour market prospects. Good or very good labour market prospects are expected for as many as 74 of the 98 types of education. There are types of education at every educational level, except for the lowest (only primary education), with good labour market prospects. But it is particularly in higher education where there are many types of education for which good to very good labour market prospects can be expected. In fact for people with higher education the labour market prospects are good in almost every case.

Table 5 gives an overview of the types of education for which the labour market prospects are very good. It can be seen from the table that the group of types of education with very good prospects does not include any types of education at Preparatory Vocational Education level or lower. It is striking that relatively more types of education in the higher educational levels have very good prospects. For example at the HGSE and Intermediate Vocational Education level, four of the 31 differentiated types of education have very good prospects. At the HVE level, where a total of 33 types of education are differentiated, there are six types of education in the group with very good prospects. At the university level, six of the 18 differentiated types of education have very good prospects.

The types of education with very good prospects at Intermediate Vocational Education level are not concentrated in a particular field of study. Labour market prospects are very good for both the technical types of education Operational technology and Process technology 
and for the types of education Nursing and Hotel and catering. For these types of education it is mainly the expansion demand which is responsible for the heartening prospects. These types of education are characterized by a relatively high or very high expansion demand, which is in all cases higher than the replacement demand. Moreover the flow of students entering the market ranges from average to very low.

Table 5

Types of education with very good labour market prospects in 2002

\section{IVE/HGSE}

$\begin{array}{ll}\text { IVE, Operational technology } & 0.80\end{array}$

IVE, Process technologies $\quad 0.81$

$\begin{array}{ll}\text { IVE, Nursing } & 0.81\end{array}$

$\begin{array}{ll}\text { IVE, Hotel and catering } & 0.85\end{array}$

HVE

HVE, Law and public administration $\quad 0.69$

HVE, Transport and logistics $\quad 0.80$

HVE, Construction and civil engineering $\quad 0.83$

HVE, Teacher training, commerce and social studies $\quad 0.85$

HVE, Agriculture and animal husbandry $\quad 0.85$

$\begin{array}{lr}\text { HVE, Information science } & 0.85\end{array}$

UE

$\begin{array}{ll}\text { UE, Accountancy and taxation } & 0.67\end{array}$

$\begin{array}{lr}\text { UE, Civil engineering } & 0.73\end{array}$

$\begin{array}{ll}\text { UE, Architecture } & 0.78\end{array}$

$\begin{array}{ll}\text { UE, Information science } & 0.78\end{array}$

$\begin{array}{ll}\text { UE, Management science } & 0.78\end{array}$

$\begin{array}{ll}\text { UE, Dentistry } & 0.81\end{array}$

Abbreviations: see table 4

Source : ROA

At Higher Vocational Education level there are also very good labour market prospects for people from very divergent types of education. The types of education at this level show fewer common features than those in Intermediate Vocational Education as regards the underlying causes of the very good prospects. For HVE, Teacher training, commerce and social studies and for HVE, Transport and logistics it is the higher than average replacement demand in combination with the low flows of students entering the labour market which ensure that the prospects are very good. For HVE, Agriculture and animal 
husbandry, there are many students entering the labour market, but this is counterbalanced by a high or very high expansion and replacement demand. The situation for HVE, Construction and civil engineering is similar: here again the large group of school-leavers flowing in can count on a more than adequate number of job openings.

HVE, Information science has very good prospects because the expansion demand is very high. On the other hand the replacement demand for people with HVE training in IT is low because this is a relatively new type of education. For HVE, Law and public administration very good prospect are expected for the same reasons. Here again there are very low flows of students entering the labour market, replacement demand is average and expansion demand is high.

\section{Types of education with bad labour market prospects}

Table 6 gives an overview of the types of education for which the expected labour market prospects are bad, despite the generally favourable developments in the labour market. This is the case for only five types of education in all.

Table 6

Types of education with bad labour market prospects in 2002

Type of education

LGSE, PVE

PVE, Utilities installation

PVE, Administration, commerce and textiles

PVE, Hotel, catering and food technology

IVE, HGSE

IVE, Tourism and recreation

HVE

HVE, Personnel management

LGSE $=$ Lower General Secondary Education

PVE = Preparatory Vocational Education

IVE = Intermediate Vocational Education

HGSE = Higher General Secondary Education

Source : ROA

The types of education with bad prospects are predominantly those at a lower or inter- 
mediate level. Within Preparatory Vocational Education there are three types of education with bad prospects. In Intermediate Vocational Education only one type of education has bad labour market prospects. PVE, Utilities installation has bad prospects because the flow of students entering the labour market is very high. PVE, Hotel, catering and food technology and PVE, Administration, commerce and technology, in contrast, have bad prospects as a result of a marked contraction in the demand. As already noted in this chapter, school-leavers from PVE, Administration, commerce and technology are already suffering from a very high unemployment rate.

The very high inflow of school-leavers from IVE, Tourism and recreation, at more than 9\% per year, and the very low replacement demand mean that for the coming period the labour market prospects for this type of education are expected to be bad. The HVE training in Personnel management is the only type of tertiary education with bad prospects as a result of a very high inflow.

\section{Labour market prospects by educational level}

At every educational level except for primary education there are fields of study with both good and bad labour market prospects. However with the exception of primary education, the prospects at all levels are on average good (see table 7).

\section{Table 7}

Future labour market prospects per educational level, 1997-2002

\begin{tabular}{lccccl}
\hline $\begin{array}{l}\text { Educational } \\
\text { level }\end{array}$ & $\begin{array}{c}\text { job openings } \\
\%\end{array}$ & $\begin{array}{c}\text { passive } \\
\%\end{array}$ & $\begin{array}{c}\text { substitution } \\
\%\end{array}$ & IFLM & char. \\
\hline Primary education & 23.3 & 32.8 & 0.3 & 1.07 & moderate \\
PVE, LGSE & 31.2 & 26.2 & -3.9 & 0.99 & good \\
IVE, HGSE & 33.7 & 30.3 & -0.7 & 0.98 & good \\
HVE & 34.1 & 21.4 & 1.1 & 0.90 & good \\
UE & 38.2 & 32.1 & 5.0 & 0.93 & good \\
\hline
\end{tabular}

Abbreviations: see Table 4

Source : ROA

The ROA forecasts for the period $1995-2000^{19}$ already pointed to favourable prospects, especially for higher education. On the basis of the current forecasts, this trend may be expected to continue. Clear improvements are also expected in the labour market prospects of Intermediate Vocational Education (including apprenticeships) and Higher

19. ROA (1995). 
General Secondary Education.

However as has been noted above there may be markedly different labour market prospects within different educational levels. With the exception of primary education, there are types of education with good to very good prospects and others with moderate or bad labour market prospects at every educational level.

Table 8 shows that the percentage of school-leavers with a type of education with bad or moderate labour market prospects declines as the educational level rises. School-leavers with no more than primary education have moderate labour market prospects, as has already been seen in table 7 .

Table 8

Percentage of school-leavers with types of education for which bad or moderate labour market prospects are expected, per educational level

Educational level $\quad \%$

$\begin{array}{lr}\text { Primary education } & 100.0 \\ \text { PVE, LGSE } & 21.5 \\ \text { IVE, HGSE } & 12.9 \\ \text { HVE } & 6.2 \\ \text { UE } & 1.7\end{array}$

PVE = Preparatory Vocational Education

LGSE = Lower General Secondary Education

IVE = Intermediate Vocational Education (includes apprenticeships)

HGSE = Higher General Secondary Education (includes Pre-university Education)

HVE = Higher Vocational Education

UE = University Education

Source : ROA

Although the average labour market prospects at Preparatory Vocational Education and Lower General Secondary Education level are good, more than $20 \%$ of the school-leavers at this level have followed a type of education with bad or moderate prospects. This relates especially to the school-leavers of the Preparatory Vocational Education courses in Utilities installation; Bakery; Hotel, catering and food technology and Administration, commerce and textiles. In contrast, the prospects for school-leavers from Lower General Secondary Education and from the PVE courses in Agriculture, Transport, Security and the diverse technical types of education are good.

Graduates from Intermediate Vocational Education or apprenticeship and from Higher General Secondary Education also have good average labour market prospects. About 
$13 \%$ of the school-leavers at this level will be confronted with moderate or bad prospects in the labour market. Especially for graduates from IVE, Tourism and recreation, the prospects are not very hopeful. To a lesser extent that also applies for the IVE courses in Printing technology, Physical therapy, Nursing and for courses training students to be doctor's, dentist's or vetinary assistants. There are very favourable prospects at this level for those with an education in operational technology, process technologies, medical technology, nursing and hotel and catering.

At the Higher Vocational Education level only $6.2 \%$ of the school-leavers have taken a type of education which is less favourable, at least as regards its labour market prospects. This relates to students from HVE, Personnel management or HVE, Environmental studies and food technology. The HVE courses which offer very favourable prospects are very diverse: radiology, agriculture and animal husbandry, information science, transport and logistics, Teacher training in commerce and social studies, law and public administration and construction and civil engineering.

Finally, of those with university education, only graduates from art history and theory have moderate prospects on the labour market. However in the coming period they account for only $1.7 \%$ of the flow entering the labour market from university education. Architectural studies at this level also offer very good prospects on the labour market, as do courses in civil engineering, information science, accountancy and taxation, dentistry and business administration.

\subsection{Recruitment problems}

If a particular type of education offers good or very good labour market prospects, it will be fairly easy for school-leavers with this educational background to find a job at the level and in the field which was anticipated when they began their study. On the other hand employers will find it difficult to recruit school-leavers with this educational background. Thus good labour market prospects for school-leavers will normally correspond with considerable problems for employers in finding personnel.

An indicator of the future recruitment problems (IFRP) has been devised in order to be able to provide an indication of possible future problems in recruiting graduates from the various types of education (see equation 5.8). This indicator differs from the IFLM only for those types of education for which the employment level is declining. In that case businesses will naturally take the opportunity to reduce the undesired outflow of existing personnel, which will mean that fewer newcomers will be required. If the IFRP is less than or equal to 1.00, the expected problem areas in the supply of personnel are characterized as large. If the IFRP is less than 0.95 , this is characterised as a very large risk of problem areas in the supply of personnel. 
In discussing the types of education for which problem areas in the supply of personnel are expected, an indication will be given in each case of the economic sectors which will probably have to deal with these problems. ${ }^{20}$ Just as unfavourable labour market prospects for newcomers to the labour market do not automatically result in high unemployment, problem areas in the supply of personnel cannot be simplistically equated with vacancies which cannot be filled. Businesses can respond to such problems in various ways: by offering a higher wage, improving the image of the job, by recruiting workers with another educational background, by working overtime, etc. Problem areas in the supply of personnel are therefore indicative in the first place of an increase in the costs or efforts which a business will have to make if they want to recruit a worker from that type of education.

For each economic sector, table 9 gives an overview of the types of education for which that sector will be confronted with very large problems in the supply of personnel. Very large problem areas can be expected mainly for graduates from tertiary education, and are concentrated mainly in the sectors of Business services, Health care and the Civil service. However that does not mean that no problem areas are expected for intermediate types of education in other economic sectors. For example, in the Commerce sector large problem areas are also to be expected for graduates from Lower General Secondary Education; PVE, Electrical trades and PVE, Nursing.

However it is not only higher types of education for which very large problem areas in the supply of personnel are expected. There are also a number of types of education at the intermediate level for which very large problem areas are expected in particular sectors. That is the case in the Heavy chemicals industry, where very large problem areas in the supply of personnel with Preparatory Vocational Education in Process technologies are expected. A number of very large problem areas may also be expected in the sectors Construction, Commerce, Hotel and catering, and Health care, for types of education at the intermediate level. In the Construction sector the expected problems relate to IVE, Operational technology. In the other three economic sectors (Commerce, Hotel and catering and Health care) very large problem areas in the supply of personnel of intermediate educational level are expected for IVE, Hotel and catering.

In the Construction sector very large problem areas in the supply of personnel are expected to result from the inadequate flow of graduates from HVE, Construction and civil engineering. Very large problem areas will arise in the economic sector of Commerce in relation to graduates from HVE, Information science. Of those already in the labour market with this educational background, $12 \%$ are working in this sector. Four economic sectors

20. In the meantime we have had to apply a simple criterion, mentioning only those economic sectors in which at least $5 \%$ of the workers with the educational background concerned are employed. 
face very large problem areas in the supply of personnel from HVE, Transport and logistics. The problems will be most strongly felt in the economic sector of Shipping and aviation because the employment share of this type of education in that sector is fairly high, at $15 \%$.

Business services is the economic sector with the greatest number of types of education which are expected to produce problem areas: very large recruitment problems may be expected in this sector for graduates from four courses in Higher Vocational Education and five university courses. The HVE courses with very large problem areas are HVE, Teacher training, commerce and social studies; HVE, Construction and civil engineering; HVE, Information science and HVE, Law and public administration. Much of the demand for workers with an educational background in HVE, Construction and civil engineering or HVE, Information science comes from the sector of Business services.

Table 9

Very large problem areas in the supply of personnel in the medium term, by economic sector

Economic sector

expected problem areas

Heavy chemicals industry

Energy

Construction

Commerce

Shipping and aviation

Road and rail transport

Hotel and catering

Business services
Health care

Education

Civil service
IVE, Process technologies

HVE, Transport and logistics

IVE, Operational technology

HVE, Construction and civil engineering

IVE, Hotel and catering

HVE, Information science

HVE, Transport and logistics

HVE, Transport and logistics

IVE, Hotel and catering

HVE, Teacher training, commerce and social studies

HVE, Construction and civil engineering

HVE, Information science

HVE, Law and public administration

UE, Architecture

UE, Civil engineering

UE, Information science

UE, Management science

UE, Accountancy and taxation

IVE, Nursing

IVE, Hotel and catering

HVE, Teacher training, commerce and social studies

UE, Dentistry

HVE, Teacher training, commerce and social studies

HVE, Teacher training, commerce and social studies

HVE, Construction and civil engineering

HVE, Information science

HVE, Transport and logistics

HVE, Law and public administration 
Source : ROA

Business services will also experience large problems in recruiting people with university education in Architecture; Civil engineering; Information science; Management science and Accountancy and taxation. It is striking that many of the workers with these educational backgrounds work in the Business services sector.

In addition to the expected problem areas for the type of education IVE, Hotel and catering which have already been mentioned, three other very large problem areas can be expected in the Health care sector. The very large problems in the supply of personnel from IVE, Nursing will be almost entirely concentrated in this sector. In fact more than $85 \%$ of the workers with an educational background in IVE, Nursing work in the Health care sector. Problem areas are also expected for HVE, Teacher training, commerce and social studies and UE, Dentistry.

For the Education sector, a very large recruitment problem is expected for personnel from the HVE, Teacher training, commerce and social studies. Other large problem areas are expected in this sector for the other teacher training courses at the HVE level.

The Civil service sector is also expected to suffer very large recruitment problems in relation to HVE, Teacher training, commerce and social studies. However it is noticeable that the very large problem areas expected in this sector relate mainly to the HVE types of education. For example, very large problem areas are expected for HVE, Construction and civil engineering; HVE Information science; HVE, Transport and logistics and HVE, Law and public administration. The Civil service sector is very important for graduates from HVE, Law and public administration. In fact $48 \%$ of those already working with this qualification work within the civil service. UE, Accountancy and taxation is the only type of education at the university level for which very large problem areas are expected in the Civil service sector.

As already indicated, employers may recruit workers with divergent educational backgrounds when they are seeking new personnel for various occupational groups. In practice these possibilities for substitution will be utilized to reduce the recruitment problems. However in some cases this will have to be accompanied by supplementary training or the complete retraining of people with a different educational background. But there are some occupations, especially in the Non-commercial services sector and the Civil service, for which this flexibility seems extremely limited. That means that for these occupations, which include the medical occupations and primary and secondary school teachers, the expected problem areas in the supply of personnel will probably be very acute. 


\section{Sensitivity to cyclical fluctuations and opportunities to switch}

A bad labour market situation may be the result of a structurally weak labour market position for that type of education. However the reverse is not always true: a type of education with a structurally weak position need not be continually confronted with excess supply. For example, if the employment for a particular type of education is very sensitive to the state of the business cycle, the labour market situation may be temporarily favourable because the business cycle is close to its peak. In order to be able to give a better picture of the vulnerability of the various types of education, this section examined the more or less structural characteristics of their labour market positions, which give an indication of the labour market risks involved in the choice of a particular type of education.

The labour market risk entailed in a particular educational choice is in the first place manifest in the degree to which employment levels for those with that educational background are susceptible to fluctuations in the business cycle. If there are strong swings in the level of employment for people with a particular type of education, there is a risk that those who may choose this type of education when the economic tide is favourable may find that their labour market prospects when they graduate are bad, because the economy may then be at a low ebb. In that case there is also an uncertain employment situation in the longer term, because of the greater risk of losing one's job in the future if the business cycle turns downward.

Of course labour market risks are not limited to the effects of cyclical fluctuations on employment levels. The degree to which school-leavers are dependent on the employment prospects in only a few occupations or economic sectors is also an important risk factor. This risk is high especially for types of education which are specifically focused on functions in a particular submarket. On the other hand, if the employment prospects in a particular occupational group are less favourable, those who have taken a type of education which enables them to find work in diverse occupations and economic sectors will find it relatively easy to switch to occupations for which the movement in employment levels is more favourable. Moreover those who have chosen these types of education also have more flexibility in the labour market if they gain more insight during their study or working career into their personal capacities and preferences, which may perhaps mean that career prospects which originally appeared attractive become less appealing.

However a broad education is not positive in all respects. If there are many opportunities to switch, this also implies that the school-leavers will face more competition in the labour market from other types of education. Moreover, broadening a type of education may entail decreased specialisation, reducing the productivity (that is, the ability to set the graduates or school-leavers to work without further training). The importance of switching opportunities in the labour market must therefore be seen mainly in relation to the risk of unstable employment levels. 
Figure 9 gives an overview of the degree to which workers with a particular educational background face the two named labour market risks. The indicators for the two risks have been calculated according to equations 5.10 (cyclical sensitivity) and 5.11 (possibility of lateral mobility). The results are grouped in four quadrants. Table 10 gives an overview of the differentiated types of education with their code numbers. Quadrant II contains the types of education facing the highest labour market risks. These types of education suffer from both high sensitivity to the state of the business cycle and few opportunities to switch to occupations at a corresponding level.

Such dual risks are faced by PVE, Construction trades (1); IVE, Utilities installation (7); IVE, Printing technology (8); IVE, Process technologies (9); HVE, Construction and civil engineering (16); HVE Information science (17) and HVE, Accounting and business economics (20). PVE, Construction trades and IVE, Utilities installation have the greatest sensitivity to the state of the business cycle of this group. HVE, Information science, in contrast, offers very few opportunities to switch because the training given in this type of education can be used in only a small number of occupational groups.

Table 10

Overview of the differentiated types of education, with numerical codes.

PVE, Construction trades

PVE, Hotel, catering and food technology

PVE, Administration, commerce and textiel

PVE, Community care, Hotel and Catering

HGSE

IVE, Agriculture and animal husbandry

IVE, Utilities installation

IVE, Printing technology

IVE, Process technologies

IVE, Medical, dental and vetinary assistant $\quad 10$

IVE, Nursing $\quad 11$

IVE, Hairdressing 12

IVE, Tourism and recreation $\quad 13$

HVE, Teacher training, primary education $\quad 14$

HVE, Environmental studies and food technology $\quad 15$

HVE, Construction and civil engineering 16

HVE, Information science $\quad 17$

HVE, Chemical engineering $\quad 18$

HVE, Nursing 19

HVE, Accounting and business administration $\quad 20$

HVE, Social work $\quad 21$

HVE, Performing and visual arts 22

UE, Economics and econometrics 23 
Source : ROA

The types of education in quadrant III are largely free of both labour market risks. They have both a low sensitivity to the state of the business cycle and many opportunities to switch to occupational groups at a function level which matches their educational level. This favourable risk position is found for PVE, Community care, hotel and catering (4); PVE, Administration, commerce and textiles (3) and HVE, Environmental studies and food technology (15).

\section{Figure 9}

Labour market risks for school-leavers from 24 types of education on the basis of sensitivity to the state of the business cycle and occupational dispersion, 1995-1996*

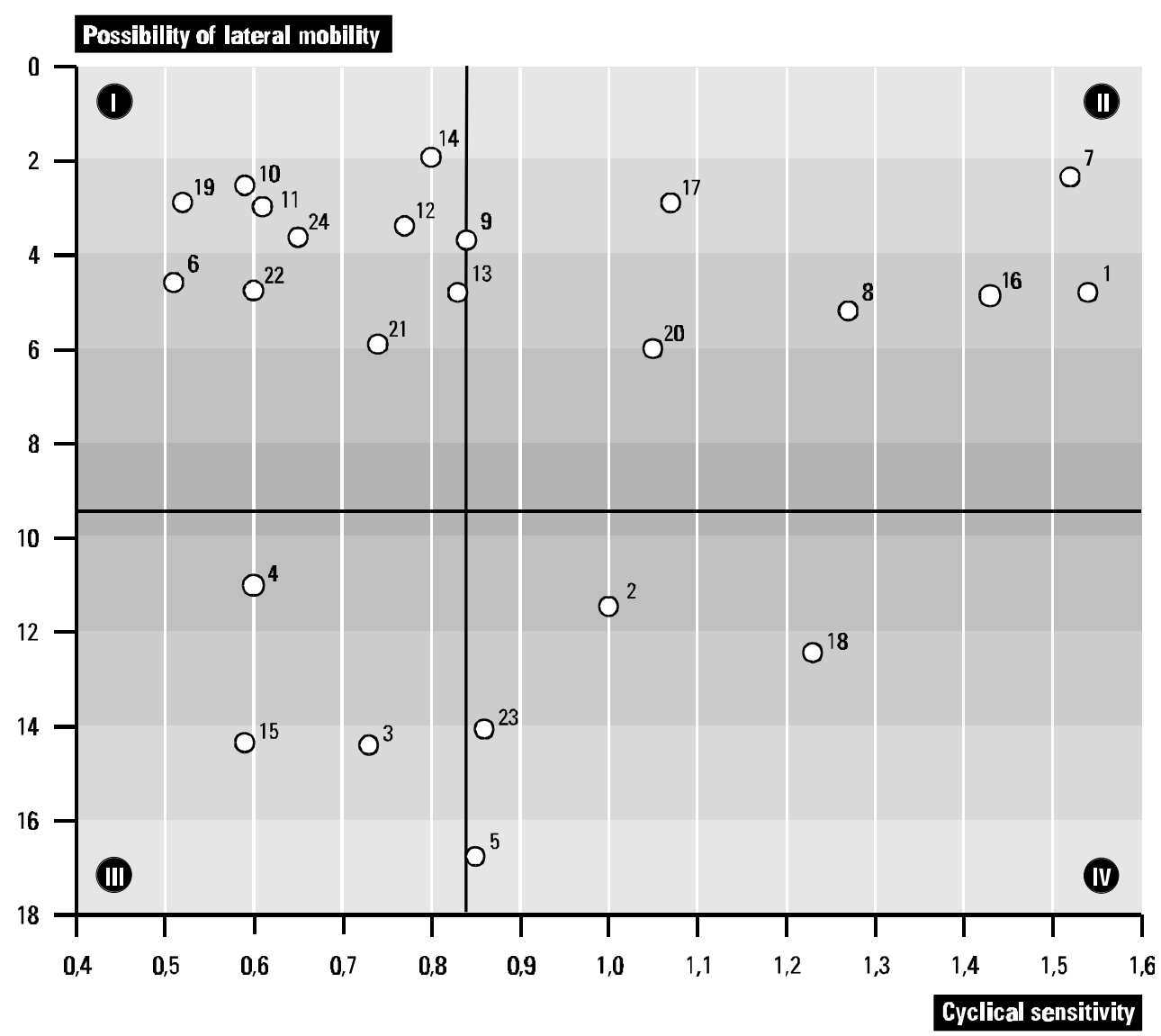

Source: ROA (1997)

For the other types of education it is not possible to give a simple description of the labour market risks which people with that educational background may generally face. The types of education in quadrant I have only slight opportunities to switch to other occupations at a matching function level. However these limited opportunities to switch will generally not be a problem, given the relatively stable employment levels in the occupational domain of 
these types of education. These are all types of education at the intermediate or higher level. There are five courses in Intermediate Vocational Education which have a low sensitivity to the state of the business cycle combined with few opportunities to switch: IVE, Agriculture and animal husbandry (6); IVE, Doctor's, dentist's and vetinary assistant (10); IVE, Nursing (11); IVE, Hairdressing (12) and IVE, Tourism and recreation (13). The four types of training at Higher Vocational Education level which suffer little from fluctuations in the business cycle, but can hardly switch to other occupations, are HVE, Teachers training, primary education (14); HVE, Nursing (19); HVE, Social work (21) and HVE, Performing and visual arts (22). Finally, employment for people with UE, Accountancy and taxation (24) also has a low sensitivity to the state of the business cycle, but this is combined with few opportunities to switch.

The types of education in quadrant IV, in contrast, face strong fluctuations in employment levels in accordance with the business cycle. However if the employment situation for these types of education is unfavourable at a particular moment, this can probably be absorbed to some extent because it is fairly easy to switch to other occupations at a similar level. This situation is found for PVE, Hotel, catering and food technology (2); HGSE (5); HVE, Chemical engineering (18) and UE Economics and econometrics (23). Of these types of education, HGSE is in the most favourable position. Partly as a result of the general character of this type of education, the opportunities to switch are the highest of all the types of education differentiated in figure 9, while the sensitivity to the state of the business cycle is not much higher than average.

\section{Evaluation}

As mentioned in section 4.1, periodic evaluations of the forecasts are not only important for indicating the validity of the forecasting model. They are also considered as an important means of further improving the quality of the forecasts. Thus far, ROA's forecasts have be evaluated twice. The most recent evaluations refer to the forecasts for the period 1989$1994^{21}$ (Borghans et al., 1996). Here we will focus on the evaluation of the forecasts of the IFLM as this is the major signal for students who are to chose a particular study.

Because the IFLM indicates how the labour market position of a type of education develops in relation to the situation in the base year, the IFLM should also be evaluated by comparing the labour market position by type of education in 1994 with that of 1989 . However, there is no good information available on the labour market position of schoolleavers in 1989. For 1994 the Higher Vocational Education Monitor (HBO-monitor) and

21. These earlier forecasts did not include the IFRP indicator which signals future recruitment problems. 
RUBS school-leaver survey can be used. ${ }^{22}$ So the developments in the labour market position by type of education in the period from 1989 to 1994 will not be examined, but the labour market position among the types of education in 1994 will be analyzed. The implicit assumption is that all types of education react in the same way to labour market discrepancies. On the basis of the data from the RUBS and Higher Vocational Education monitor, the relationship with the IFLM is estimated for different aspects of the labour market position. ${ }^{23}$ The following labour market aspects were taken into account (also see Wieling and Borghans, 1995): the unemployment percentage at the moment the survey was conducted; the percentage of school-leavers who were unemployed for more than four months after graduation; the percentage of school-leavers who were overeducated for the jobs they have; the percentage of school-leavers with full-time jobs; the percentage of school-leavers with part-time jobs, ${ }^{24}$ and the percentage of school-leavers with relatively low wages. ${ }^{25}$ For each aspect, the following equation was estimated:

$y_{e}^{k}=\alpha^{k}+\beta^{k} *\left(I F L M_{e}-1\right)$

Where:

$\mathrm{y}_{\mathrm{e}}{ }^{\mathrm{k}}=$ labour market aspect $k$ for type of education $e$.

By linking the IFLM in the equation to the situation in which supply and demand are in balance (IFLM=1), $\alpha^{k}$ can be interpreted as the natural scope of the indicator in question. $\beta^{k}$ indicates how the indicator changes due to changing prospects. Table 11 gives the results of the individual estimates. ${ }^{26}$ There appears to be a positive relation between the IFLM and the unemployment percentage. However, the effect is not significant. This is also true for the percentage of school-leavers who were unemployed for more than four months after graduation. To the extent that the expected future labour market prospects were worse, the percentage of overeducation observed in 1994 is also higher. The percentage of part-time workers also increases when the IFLM is higher. As was expected, the percentage with full-

22. The RUBS school-leavers survey was also conducted in 1989. Due to differences between the surveys of 1989 and 1994 it is not possible to make reliable comparisons between the two years.

23. Information is available only for school-leavers from General Secondary Education, PVE, IVE and HVE. The IFLM for university and primary education can therefore not be calculated.

24. Part-time work need not of course be involuntary. The school-leaver may desire that situation. Because the percentage of part-time workers is correlated with the labour market prospects, this factor refers only to the variation in part-time work that can be explained on the basis of the labour market situation.

25. A relatively low wage means a wage lower than $\mu-0,524 * \sigma$, where $\mu$ is the average wage of school-leavers with the type of education in question and $\sigma$ the standard deviation (see Wieling et al., 1990).

26. In fact, it involves a system of equations that could be estimated simultaneously. A possible correlation between the disturbance terms, i.e. $E\left[\varepsilon_{j}^{k} \varepsilon_{j}^{l}\right]=\sigma_{k l}$, does not, however, have an effect on the results of the estimate because the regressors for all the equations are equal. 
time jobs decreases to the extent that the future labour market prospects were worse. The percentage of school-leavers with low wages is correlated negatively with the IFLM, but this effect too is not significant. It can be concluded that discrepancies between supply and demand do not necessarily lead to unemployment, but that a poorer labour market position is primarily reflected in more under-utilisation and more part-time work. This result confirms the findings of Wieling and Borghans (1995).

In order to determine how well the IFLM predicted the future labour market situation, all the aspects of this labour market situation must be considered simultaneously. That is why a regression equation was estimated in which the IFLM is explained on the basis of the above-mentioned indicators of the labour market situation. ${ }^{27}$ The realisations of the IFLM have been determined on the basis of the equation. The $\bar{R}^{2}$ of this estimate can be compared with the score relationship according to score $=1-\bar{R}^{2}$. Since the $\bar{R}^{2}$ is 0.20 the score calculated in this way would be 0.80 . In the previous forecast for 1992 this score was 0.91 .

Table 11

Relation between predicted labour market position and current labour market situation

Labour market situation indicator

$\alpha \quad \mathrm{t}$-value $\quad \beta \quad \mathrm{t}$-value

Unemployed

0.10

$8.96^{* *}$

0.04

0.45

$>4$ months unemployed after graduation

$0.1610 .92^{* *}$

0.

0

8 0.69

Overeducation

0.27

$9.75^{* *}$

0.38

$1.83^{*}$

Part-time job

0.34

$7.71^{* *}$

0.73

$2.25^{* *}$

Full-time job

0.57

$20.34^{* *}$

$-0.20 \quad 0.94$

Low wage

0.22

$8.91^{* *}$

$\begin{array}{ll}-0.00 & 0.03\end{array}$

* significant at $90 \%$ reliability

** significant at $95 \%$ reliability

Table 12 gives a comparison of the forecast and the realisation of the qualitative charac-

27. The resulting equation is as follows:

IFLM $M_{i}=0.75+0.52 *$ unemp $_{4}+0.28 *$ overed $_{i}+0.25 *$ ptime $_{i}+0.06 *$ perm $_{i}-0.01 *$ Iwage $_{i}$

where $I F L M_{i}$ is the indicator for future labour market prospects till 1994 for type of education e, unempl$/ 4_{i}$ is the percentage of school-leavers who are unemployed for more than 4 months after graduation, overed ${ }_{i}$ is the percentage of school-leavers who are overeducated, ptime is the percentage of school-leavers with part-time jobs, perm $m_{i}$ is the percentage of school-leavers with permanent jobs, and Iwage is the percentage of school-leavers with low wages. Compared to equation (9.1), the explanatory variable and the variable to be explained have been switched here. For it is not a question of a causal relationship but the extent to which separate indicators supply information about the most plausible values of the 'realisation' of the IFLM that was not directly observed. 
terisations of the labour market prospects. However, it should be borne in mind that the comparison which determines the weight of the various indicators of the labour market situation is estimated on the basis of the forecasts. It is assumed that the prediction errors are expected to be 0 . Not only the forecasts but also the estimated realisations contain uncertainty. Discrepancies between the forecast and realisation can therefore also be the cause of an inaccurate determination of the realised prospects.

From the table it appears that the predicted characterisations of the labour market prospects of the various types of education were quite good. For 14 of the 31 types of education for which information on the current labour market position was available, the qualitative characterisation of the forecast corresponds exactly with the realisation. ${ }^{28}$ That is about $45 \%$ of the types of education. Even taking account of the types of education that are predicted in categories that are contiguous to the realised category, it appears that the future labour market position was characterised reasonably accurately for about $90 \%$ of the types of education. There are only two types of education for which the realisation has the opposite sign to the forecast. For IVE, Community care good labour market prospects were predicted, whereas the realisation was poor. On the other hand, for HVE, Agriculture poor prospects were predicted, whereas the realisation was reasonable.

Table 12

Characterisation of labour market indicator IFLM and estimated realisations

\begin{tabular}{lccccc} 
Forecast & Good & Reasonable & $\begin{array}{c}\text { Realisations } \\
\text { Moderate }\end{array}$ & Poor & Total \\
\hline Good & 8 & 5 & 0 & 1 & 14 \\
Reasonable & 1 & 1 & 3 & 0 & 5 \\
Moderate & 1 & 3 & 1 & 0 & 5 \\
Poor & 0 & 1 & 2 & 4 & 7 \\
Total & 10 & 10 & 6 & 5 & 31 \\
\hline
\end{tabular}

The quality of the forecasts of the labour market prospects till 1994 has also clearly improved as compared to the forecasts of the prospects till 1992. From the evaluation of the forecasts till 1994 it appeared that for about $70 \%$ of the types of education the labour market prospects were predicted reasonably well at the time. Aside from the improved demand and supply forecasts, the different calculation method for the prospects may also explain this improvement as the IFLM is less sensitive to slight fluctuations in the demand

28. As has been said, insufficient information is available on the current labour market position of UE graduates. Consequently, the forecasts of the labour market prospects for university education cannot be evaluated. 
and supply forecasts than the previously used measure of future prospects. It should be borne in mind, however, that the realisations of the forecasts can now be measured better than in the evaluation of 1992 because more information is now available on the current labour market position of school-leavers.

Although some components of the forecasts were not equally satisfactory for all the occupations or types of education, the labour market prospects for the types of education appear to be predicted reasonably well. One reason for this is that prediction errors in a specific component are frequently offset by prediction errors in another component, since prediction errors in different components are often negatively correlated. Moreover, the forecasts by type of education seem to be better than the forecasts by occupational class. Not all the errors in the forecasts by occupational class have an effect on the forecasts by type of education. Also, both the labour market inflow and the replacement demand are components with a high degree of reliability. Uncertainties in the expansion demand are usually not so large that they can outweigh the two rather strong forecast components mentioned above.

\section{Conclusions}

This paper has discussed the manpower forecasting model developed by ROA, which goes several steps beyond the scope of the traditional manpower requirements approach. In this paper we have dealt particularly with the objectives, the basic principles, the theoretical foundations and the general structure of ROA's labour market information system approach and the central labour market indicators. To illustrate the capacity of the forecasting model to distinguish the various components of expansion demand, the employment forecasts by type of education for the period 1997-2002 have been presented. Moreover, an impression was given of the evaluation of the previous forecasts.

The steps taken by ROA to transcend the traditional manpower requirements approach can be summarized as follows:

- a change from a planning tool to a transparency approach;

- a better theoretical foundation;

- an extension of the manpower forecasts into a 'labour market information system' ;

- improved data input;

- the use of occupational and educational classifications, which distinguishes homogeneous groups of workers;

- the use of more sophisticated econometric models.

Although progress has been made on several points and the methodology which has been developed consists of a logically designed structure of procedures and models, further improvements in both the quality and the utility of the information generated by ROA's 
labour market information system approach will remain an important goal. These further improvements include:

- to increase the explanatory power of the forecasting models, particularly of expansion demand and the inflow of newcomers on the labour market. Thus far, the forecasting model for the inflow of newcomers lacks any explanatory variables. A first step in the development of an explanatory model would probably be the introduction of a 'discouraged workers effect' with respect to the choice between further full-time education and labour market entrance. The educational model of expansion demand should be more explicitly based on the theoretical foundations developed with respect to the distances between the various types of education in relation to the comparative advantages of the various educational backgrounds of workers and the adjustment processes facilitated by the additional training of workers with an educational background that does not perfectly match the skill requirements in the occupation concerned.

- to improve the consistency between the models for expansion and replacement demand for types of education which face declining employment levels.

Moreover, it is the intention to develop the sectoral approach of the information system further in the coming years, and to put more emphasis on questions of recruitment problems and the (re)training of unemployed and employed workers in relation to the recruitment problems expected in the various labour market segments. The usefulness of the labour market information for the human resource management of firms will also be increased by incorporating the expected adjustment processes of firms in case of a gap between ex ante supply and demand in a similar way as estimated in Wieling and Borghans (1995) with respect to the adjustment processes from the point of view of the actors on the supply side of the labour market.

Attention will also be paid to the regionalisation of the labour market information broken down by economic sector, occupation and education. Recently a major step in this direction has been made in the Regional Labour Market Information Limburg (RAIL) project. In this project for the first time regional labour demand and supply forecasts have been made for one of the provinces of the Netherlands (van Eijs et al., 1998).

Finally, attention will be given to the international context relevant to the supply and demand in the Dutch labour market, which will probably become more important due to the integration process of the national labour market in the European Union. First steps in this field have been undertaken in Teunis and de Grip (1996) and de Grip et al. (1996).

\section{References}

Beekman, Th., R. Dekker, A. de Grip, H. Heijke (1991), An Explanation of the Educational Structure 
Occupations, Labour 5 (3), pp. 151-163.

Berendsen, H., R.J.P. Dekker, A. de Grip, P.J.E. van de Loo (1992), Prognose arbeidsmarktinstroom van schoolverlaters per opleidingstype, ROA-W-1992/2, Research Centre for Education and the Labour Market, Maastricht.

Blaug, M., (1967), Approaches to Educational Planning, Economic Journal 77 (June), pp. 262-287.

Borghans, L. (1992) A Histo-Topographic Map of Dutch University Studies, ROA-W-1992/5E, Research Centre for Education and the Labour Market, Maastricht.

Borghans, L., (1993), Educational Choice and Labour Market Information, dissertation University of Limburg, Research Centre for Education and the Labour Market, Maastricht.

Borghans, L., H. Heijke (1994), Een random coëfficiënten model voor het voorspellen van de beroepenstructuur van bedrifstakken, ROA-W-1994/1, Research Centre for Education and the Labour Market, Maastricht.

Borghans, L., P. van Eijs, W. Smits (1996), Evaluatie arbeidsmarktprognoses naar opleiding en beroep tot 1994, ROA-R-1996/9, Research Centre for Education and the Labour Market, Maastricht.

Borghans, L., H. Heijke (1996), Forecasting the Educational Structure of Occupations: A Manpower Requirement Approach with Substitution, Labour 10 (1), 1996, pp. 151-192.

Borghans, L., et al. (1997), Methodiek arbeidsmarktprognoses en -indicatoren, 1997-2002, ROA-W1997/6, Research Centre for Education and the Labour Market, Maastricht.

Borghans, L., E. Willems (1998), Interpreting Gaps in Manpower Forecasting Models, Labour 12 (4) 1998. pp. 633-641.

CPB (1990), ATHENA: een bedrijfstakkenmodel voor de Nederlandse economie, CPB Monografie no.30, Den Haag.

Dekker, R.J.P., A. de Grip, J.A.M. Heijke (1990), An explanation of the educational structure of $S$ e C

c $\quad t$

0 of industry, Labour 4 (3), pp. 3-31.

Dekker, R, A. de Grip, H. Heijke (1993), Indicating the Future Labour Market Prospects of Occupational Groups and Types of Education in the Netherlands, in: Heijke, H. (ed.), Forecasting the Labour Market by Occupation and Education, Kluwer Academic Publishers, Boston/Dordrecht/London.

Eijs, P. van (1994), Manpower Forecasting in the Western World: the current State of the Art, ROARM-1994/1E, Research Centre for Education and the Labour Market, Maastricht.

Eijs, P. van, H. Heijke (1996), The Relation between the Wage, Job-related Training and the Quality 0 
the Match between Occupations and Types of Education, ROA-RM-1996/6E, Research Centre for Education and the Labour Market, Maastricht.

Eijs, P. van, A. de Grip, J. Delmee, J. van Loo (1998), De Limburgse arbeidsmarkt 1997-2002, ROA-

R-1998/3, Research Centre for Education and the Labour Market, Maastricht.

Grip, A. de (1987), Onderwijs en arbeidsmarkt: scholingsdiscrepanties, dissertation, Free University 0

Amsterdam, VU-uitgeverij, Amsterdam.

Grip, A. de, J.A.M. Heijke, (1988), Labour Market Indicators: an Inventory, ROA-W-1988/1E,

$\mathrm{R}$

e s

e

a

C

$\mathrm{h}$

Centre for Education and the Labour Market, Maastricht.

Grip, A. de, L.F.M. Groot, J.A.M. Heijke (1991), Defining occupational groupings by educational structure, Environment and Planning A, 23, pp. 59-85

Grip, A. de, J.A.M. Heijke, (1991), Uitwijkmogelijkheden op de arbeidsmarkt; flexibiliteit versus produktiviteit, Onderzoek van Onderwijs 20 (February), pp. 6-8.

Grip, A. de, P. Meijboom, E. Willems (1994), Vacancies, employment growth and the demand for newcomers on the labour market, in: J. Muysken (ed.), Measurement and Analysis of Job Vacancies, Avebury, Aldershot/Brookfield (USA), pp. 101-125.

Grip, A. de, L. Borghans, E. Willems (1995), Methodology of the ROA information system on occupational groups and type of education, ROA-W-1995/1E, Research Centre for Education and the Labour Market, Maastricht.

Grip, A. de, A. Matheeuwsen, J. Hoevenberg (1996), Future job opportunities in the European Union, ROA-R-1996/5E, Research Centre for Education and the Labour Market, Maastricht.

Grip, A. de, L. Borghans, W. Smits (1998), Future developments in the job level and domain of highskilled workers, in: H. Heijke and L. Borghans (eds.), Towards a Transparent Labour Market for Educational Decisions, Ashgate, Aldershot/Brookfield (USA)/Singapore/Sydney.

Gijselaars, W.H., G. Ramaekers (1991), Studiekeuzegedrag als functie van onderwijsaanbod en arbeidsmarktontwikkelingen, in W. Smit (ed.), Aansluiting en studievaardigheid, Amsterdam, pp. 66-78.

Heijke, H. (ed.) (1994), Forecasting the labour market by occupation and education, Kluwer

$\begin{array}{lllllllll}\text { A } & c & \text { a } & d & \text { i } & \text { i } & & \text { c }\end{array}$

Publishers, Boston/Dordrecht/London.

Heijke, H., A. de Grip (1995), Mismatches between education and the labour market, in: T. Jaspers, $J$

Schippers, J. Siegers, I. van Berkel (eds.), Working Policies, Facts, analyses and policies concerning employment and non-participation in the Nehterlands, Wolters-Noordhoff, Groningen, 
pp. 51-80.

Heijke, H. (1996), Labour market information for educational investments, ROA-W-1996/2E,

$\begin{array}{lllllllll}R & e & s & e & a & r & c & h\end{array}$

Centre for Education and the Labour Market, Maastricht.

Heijke, H., A. Matheeuwsen, E. Willems (1998), Clustering educational categories in a $\begin{array}{lllllllllllll}h & e & t & e & r & o & g & e & n & e & o & u & s\end{array}$ labour market, ROA-RM-1998/2E, Research Centre for Education and the Labour Market, Maastricht.

Herweijer, L.J., J.L.T. Blank (1987), Onderwijsexpansie en werkloosheid, Tijdschrift voor Arbeids vraagstukken 3, pp. 80-86.

Hughes, G. (1993), Projecting the Occupational Structure of Employment in OECD Countries, OECD Labour Market and Social Policy Occasional Papers nr. 10, OECD, Paris.

Jong, U. de, H. Oosterbeek, J. Roeleveld, H.D. Webbink, (1992), Verder studeren, voornemens van eindexamenkandidaten 1991, Ministerie van Onderwijs en Wetenschappen, Zoetermeer.

Kodde, D.A., J.M.M. Ritzen, 1986, Vraag naar hoger onderwijs, eindrapport, Beleidsgerichte studies Hoger Onderwijs en Wetenschappelijk Onderzoek, Ministerie van Onderwijs en Wetenschappen, `s-Gravenhage.

Ministerie van Onderwijs, Cultuur en Wetenschappen (1995), Referentieraming, Zoetermeer.

OECD (1994), Employment Outlook, July 1994, Paris.

Oosterbeek, H., D. Webbink, (1995), Enrolment in Higher Education in the Netherlands, De 143 (3), pp. 367-380.

Parnes, H.S. (1962), Forecasting Educational Needs for Economic and Social Development, OECD Paris.

ROA (1995), The labour market by education and occupation to 2000, ROA-R-1995/3E, Research Centre for Education and the Labour Market, Maastricht.

ROA (1997), De arbeidsmarkt naar opleiding en beroep tot 2002, ROA-R-1997/7, Research Centre f 0

Education and the Labour Market, Maastricht.

Sanderson, J. (1987) Defining functional occupational groupings, Environment and Planning A 19, $\mathrm{p}$ $\mathrm{p}$ 1199-1220.

Sheldon, S. (1985), Die berufliche und geographische Flexibilität, Institut für Arbeitsmarkt und Berufsforschung der Bundesanstalt für Arbeit, Beitrage AB92, Nürnberg.

Shryock, H.S., J.S. Siegel (1980), The Methods and Materials of Demography, U.S. Bureau of 
the Census, U.S. Government Printing Office, Fourth Printing (rev.), Washington D.C.

Teulings, C., M. Koopmanschap (1989), An Econometric Model of Crowding Out of Lower Education Levels, European Economic Review 33, pp. 1653-1664.

Teunis, U., A. de Grip (1996), International labour market indicators, ROA-R-1996/2E, Maastricht.

Velden, R.K.W. van der, L. Borghans, Competition on the Labour Market. An Analysis of the Position of Types of Training, ROA-RM-1993/5E, Research Centre for Education and the Labour Market, Maastricht.

Verrijdt H., J. Diederen, (1987), Determinanten van beroepskeuze, OSA-Werkdocument nr. W 39,

$\mathrm{D}$ e Haag.

Webbink, D. (1998), Labour Market Forecasts and Choice of Education, in: H. Heijke, L. Borghans (eds.), Towards a Transparent Labour Market for Educational Decisions, Ashgate, Aldershot/ Brookfield (USA)/Singapore/Sydney.

Wieling, M.H., A. de Grip, E.J.T.A. Wilems (1990), Een systematische kwalitatieve typering van arbeidsmarktinformatie, ROA-W-1990/8, Research Centre for Education and the Labour Market, Maastricht.

Wieling, M.H., L. Borghans (1995), Discrepancies between Demand and Supply and Adjustment Processes on the Labour Market, ROA-RM-1995/5E, Research Centre for Education and the Labour Market, Maastricht.

Willems, E.J.T.A., A. de Grip, (1993), Forecasting Replacement Demand by Occupation and Education, International Journal of Forecasting 9, pp. 173-185.

Willems, E.J.T.A., A. de Grip, (1994), Young people and Technology, Beleidsstudies Technologie Economie 26a, Ministry of Economic Affairs, The Hague.

Wilson, R.A. (1993),Modelling and Forecasting the Structure of Employment in the United Kingdom, in: Heijke, H. (ed.), Forecasting the Labour Market by Occupation and Education, Kluwer Academic Publishers, Boston/Dordrecht/London. 